\title{
EFFECTIVE USE OF MESENCHYMAL STEM CELLS IN HUMAN SKIN SUBSTITUTES GENERATED BY TISSUE ENGINEERING
}

\author{
M.A. Martin-Piedra' ${ }^{1,2}$, C.A. Alfonso-Rodriguez ${ }^{1}$, A. Zapater ${ }^{1}$, D. Durand-Herrera', ${ }^{1,2}$, J. Chato-Astrain ${ }^{1}$, \\ F. Campos ${ }^{1,2}$, M.C. Sanchez-Quevedo ${ }^{1,2}$, M. Alaminos ${ }^{1,2, *}$ and I. Garzon ${ }^{1,2}$ \\ ${ }^{1}$ Tissue Engineering Group, Department of Histology, Faculty of Medicine, University of Granada \\ ${ }^{2}$ ibs.GRANADA, Biohealth Institute, Granada, Spain
}

\begin{abstract}
Mesenchymal stem cells (MSCs) can differentiate toward epithelial cells and may be used as an alternative source for generation of heterotypical artificial human skin substitutes, thus, enhancing their development and translation potential to the clinic. The present study aimed at comparing four types of heterotypical human bioengineered skin generated using MSCs as an alternative epithelial cell source. Adipose-tissue-derived stem cells (ADSCs), dental pulp stem cells (DPSCs), Wharton's jelly stem cells (WJSCs) and bone marrow stem cells (BMSCs) were used for epidermal regeneration on top of dermal skin substitutes. Heterotypic human skin substitutes were evaluated before and after implantation in immune-deficient athymic mice for $30 \mathrm{~d}$. Histological and genetic studies were performed to evaluate extracellular matrix synthesis, epidermal differentiation and human leukocyte antigen (HLA) molecule expression. The four cell types differentiated into keratinocytes, as shown by the expression of cytokeratin 10 and filaggrin $30 \mathrm{~d}$ post-grafting; also, they induced dermal fibroblasts responsible for the synthesis of extracellular fibrillar and non-fibrillar components, in a similar way among each other. WJSCs and BMSCs showed higher expression of cytokeratin 10 and filaggrin, suggesting these cells were more prone to epidermal regeneration. The absence of HLA molecules, even when the epithelial layer was differentiated, supports the future clinical use of these substitutes - especially ADSCs, DPSCs and WJSCs - with low rejection risk. MSCs allowed the generation of bioengineered human skin substitutes with potential clinical usefulness. According to their epidermal differentiation potential and lack of HLA antigens, WJSCs should preferentially be used.
\end{abstract}

Keywords: Mesenchymal stem cells, bioartificial skin, tissue engineering, regenerative medicine.

*Address for correspondence: Miguel Alaminos, Department of Histology, School of Medicine, University of Granada, Avda/Investigación s/n 18071, Granada, Spain.

Email: malaminos@ugr.es

Copyright policy: This article is distributed in accordance with Creative Commons Attribution Licence (http://creativecommons.org/licenses/by-sa/4.0/).

\section{Introduction}

In recent years, tissue engineering has developed as an alternative regenerative medicine approach for the clinical treatment of severe skin diseases, as it allows the efficient treatment of large and deep skin conditions (Garzon et al., 2015; Kober et al., 2016). Numerous models of human skin, generated by tissue engineering, have been developed to date (Beaudoin Cloutier et al., 2017; Bhowmick et al., 2017; Forouzandeh et al., 2010; Hartmann-Fritsch et al., 2016; Klar et al., 2018; Larouche et al., 2016; Lloyd et al., 2015; Pensalfini et al., 2017; Reuter et al., 2017; Strong et al., 2017; Vig et al., 2017). However, few clinical trials have been conducted to test the biological security (phase I and II assays) of human skin models (Boa et al., 2013; Boyce et al., 2006; Boyce et al., 1999; Boyce et al., 2017; Germain et al., 2018; Moravvej et al., 2016; Yamada et al., 2012). Most of the clinically efficient skin models are organotypic structures, consisting of a dermal substitute of dermal fibroblasts immersed in biocompatible scaffolds and an epidermal layer of keratinocytes seeded on top of the stroma. These orthotypic models show high feasibility for epidermal differentiation and maturation because differentiation of epidermal cells strongly depends on epithelial-mesenchymal interactions (Smola et al., 1993).

Development of organotypic human skin substitutes is strongly dependent on the isolation and 
culture of autologous cells, isolated and expanded in culture from healthy donor skin. However, healthy skin biopsies are sometimes difficult to obtain, especially when the patient is in a critical condition due to large-scale burns and concomitant infections. In addition, a major limitation of this technique is the time required for the isolated cells to generate a sufficient number of cells for tissue engineering, especially in the case of keratinocytes. On the other hand, epidermal keratinocytes are terminally differentiated cells that are difficult to handle in culture in the absence of feeder layers, proliferate slowly and tend to dedifferentiate in culture (Garzon et al., 2015; Kraft et al., 2012). For all these reasons, alternative cell sources allowing for the generation of human skin substitutes, without the drawbacks associated with skin biopsies, are needed for an optimal clinical translation (Bhardwaj et al., 2017).

Mesenchymal stem cells (MSCs) are adult cells with proliferation and differentiation capabilities, showing adherence to plastic, expression of specific surface markers and multipotent differentiation potential into adipocyte, chondrocyte and osteoblast lineages (Dominici et al., 2006; Kim and Park, 2017; Pittenger et al., 1999). MSCs are excellent candidates for tissue engineering applications due to their unique properties. MSCs have been described in a wide variety of human adult tissues (Gimble and Guilak, 2003). However, the four main sources of MSCs in humans are adipose-tissue-derived stem cells (ADSCs) (Zuk et al., 2002), dental pulp stem cells (DPSCs) (Gronthos et al., 2000), umbilical cord Wharton's jelly stem cells (WJSCs) (Wang et al., 2004) and bone marrow stem cells (BMSCs) (Friedenstein et al., 1976; Pittenger et al., 1999). In addition to adipocyte, chondrocyte and osteoblast differentiation potential, MSCs have epithelial differentiation capability and heterotypical models of artificial tissues could be generated using MSCs as alternative cell sources (Garzon et al., 2013). In this regard, preliminary reports support the epithelial differentiation capability of ADSCs (Baer et al., 2013) and human tooth-derived stem cells (Dogan et al., 2015). In turn, WJSCs are efficiently differentiated into cornea epithelial cells (Garzon et al., 2014) and human skin as well as oral mucosa keratinocytes (Garzon et al., 2013). BMSCs, the most characterised MSC source, can differentiate into several types of epithelial cells, including skin keratinocytes (Kokubun et al., 2016; Mahdavishahri et al., 2012; Mendez et al., 2014; Wang et al., 2014; Zhang et al., 2012). Although these previous reports support the epithelial potential of MSCs, there are no studies comparing the keratinocytic differentiation capability of the four main MSC sources for skin tissue engineering.

When compared with skin keratinocyte cultures, MSCs have important advantages, including accessibility, high proliferation rate and easy culturing, as well as very low risk of malignant transformation after allogeneic transplantation as compared to embryonic stem cells (ESCs) or induced pluripotent stem cells (iPS) (Kim and Park, 2017). In addition, one of the striking properties of MSCs, from a translational point of view, is that these cells are immunoprivileged due to the low expression of human leukocyte antigen (HLA) complex molecules and may have immunomodulatory properties (Castro-Manrreza and Montesinos, 2015; Losk et al., 2016; Shi et al., 2011). Several studies have demonstrated that MSCs can be grafted into a host patient with a low rejection risk (Casiraghi et al., 2008; Ma et al., 2017; Reinders et al., 2013). In this sense, development of human skin models using allogeneic MSCs differentiated into epidermal keratinocytes could prevent the above-described shortcomings derived from generation of autologous skin models. Thus, easier and faster generation of heterotypical models could be an advantageous approach for the translation of these advanced-therapy products as a therapeutical choice.

The aim of the present study was to compare four different models of heterotypical human bioengineered skin generated by using ADSCs, DPSCs, WJSCs and BMSCs as alternative epithelial cell sources. These models were evaluated in vitro or in vivo to determine the potential clinical usefulness of heterotypical human skin substitutes.

\section{Materials and Methods}

\section{Generation of MSC primary cell cultures}

To generate primary cell cultures of human dermis fibroblasts, skin biopsies were obtained from healthy donors. To generate primary cultures of ADSCs, WJSCs and BMSCs, small biopsies were obtained from adipose tissue, umbilical cord and bone marrow, as previously described (Alfonso-Rodriguez et al., 2015; Cejka et al., 2016; Dori et al., 2017). To generate DPSC cultures, extracted sound third molars were obtained (Garzon et al., 2017). In all cases, tissues were obtained from healthy donors subjected to surgical procedures not related to the present study. All patients gave informed consent and the study was approved by the Research and Ethics Committee of the Health System of Granada Hospitals, Spain.

Upon arrival at the laboratory, tissues were washed in phosphate-buffered saline (PBS), dissected to isolate tissues rich in MSCs and enzymatically digested for $6 \mathrm{~h}$ at $37{ }^{\circ} \mathrm{C}$ under slight agitation with a $2 \mathrm{mg} / \mathrm{mL}$ solution of Clostridium histolyticum type I collagenase (Gibco). Isolated human dermal fibroblasts and ADSCs, DPSCs and BMSCs were cultured in Dulbecco's modified Eagle's medium (DMEM; Sigma-Aldrich) supplemented with $10 \%$ foetal bovine serum (Sigma-Aldrich) and $1 \%$ antibiotic and antimycotics (100 U/mL penicillin G, $100 \mathrm{mg} /$ $\mathrm{mL}$ streptomycin and $0.25 \mathrm{mg} / \mathrm{mL}$ anphoterycin $\mathrm{B}$; Sigma-Aldrich) under standard culture conditions. WJSCs were cultured in AmnioMAX ${ }^{\mathrm{TM}}$ medium (Gibco), as previously reported (Alfonso-Rodriguez et al., 2015). Culture medium was changed three 
times a week and cells were dissociated with $0.25 \%$ trypsin-ethylenediaminetetraacetic acid (EDTA; Sigma-Aldrich) before reaching confluence.

\section{Generation of human heterotypic skin (HHS)}

HHS was developed using $24 \mathrm{~mm}$ Transwell ${ }^{\circledR}$ porous inserts with polycarbonate membranes with a pore size of $0.4 \mu \mathrm{m}$ (Costar, Corning Inc.). Briefly, a stromal substitute was generated using a mixture of human fibrin obtained from frozen plasma (Human Tissue Bank of Granada, Spain) and $0.1 \%$ type VII agarose in PBS. To produce a $5 \mathrm{~mL}$ dermal substitute, $3.8 \mathrm{~mL}$ of human plasma were added to $375 \mu \mathrm{L}$ of DMEM with 500,000 cultured skin fibroblasts. To prevent gel fibrinolysis, the mixture was supplemented with $75 \mu \mathrm{L}$ of tranexamic acid (Amchafibrin, Fides Ecopharma, Barcelona, Spain). Then, $500 \mu \mathrm{L}$ of $1 \%$ $\mathrm{CaCl}_{2}$ were added to induce fibrin polymerisation, followed by immediate addition of $250 \mu \mathrm{L}$ of melted concentrated agarose $\left(2 \%\right.$ in PBS) at $40{ }^{\circ} \mathrm{C}$. The final concentration of agarose in the stromal substitute was $0.1 \%$. Finally, the mixture was rapidly aliquoted on porous inserts and allowed to solidify at $37^{\circ} \mathrm{C}$ for $2 \mathrm{~h}$. $24 \mathrm{~h}$ after the stroma had solidified, 250,000 MSCs were seeded on top of the stromal layer to generate an epithelial-like layer consisting of each MSC type in order to generate ADSC-HHS, DPSC-HHS, WJSC-HHS and BMSC-HHS substitutes. All HHS were cultured for $7 \mathrm{~d}$ submerged in culture medium and cultured for $21 \mathrm{~d}$ following an airliquid culture technique (Garzon et al., 2014) to induce epithelial differentiation (4 weeks in total). Heterotypic artificial skin substitutes were cultured in keratinocyte inductive medium consisting of a $3: 1$ mixture of DMEM and HAM's F12 culture medium supplemented with $10 \%$ foetal bovine serum (FBS), $1 \%$ antibiotic/antimycotic solution, $24 \mu \mathrm{g} / \mathrm{mL}$ adenine, $0.4 \mu \mathrm{g} / \mathrm{mL}$ hydrocortisone, $5 \mu \mathrm{g} / \mathrm{mL}$ insulin, $10 \mathrm{ng} / \mu \mathrm{L}$ epidermal growth factor and $1.3 \mathrm{ng} / \mathrm{mL}$ triiodothyronine (all reagents were purchased from Sigma-Aldrich).

\section{In vivo evaluation}

To evaluate them in vivo, HHS were grafted in 6-weekold immune-deficient athymic nude Foxn1nu mice (Envigo, Huntingdon, UK) (Fig. 1). Briefly, mice were anesthetised using a mixture of $0.001 \mathrm{mg} / \mathrm{g}$ of bodyweight of acepromazine (Calmo-Neosan, Boehringer Ingelheim, Ingelheim am Rhein, Germany) and $0.15 \mathrm{mg} / \mathrm{g}$ of body-weight of ketamine (Imalgene 1000, Merial labs, Barcelona, Spain). Then, a skin area of $20 \mathrm{~mm}$ in diameter was surgically removed from the dorsal area of each animal and the HHS was trimmed to the same diameter. HHS samples were grafted at the injury site using absorbable suture material. A plastic ring was implanted at the injury borders and sutured using the same suture material to prevent the host skin from shrinking; the plastic ring was carefully removed after $10 \mathrm{~d}$ post-grafting. Only one graft HHS was implanted per mouse. Mice were euthanised 15 or $30 \mathrm{~d}$ after implantation of the bioengineered tissues, for histological analysis of grafted HHS and surrounding native skin. 4 mice per MSC group (ADSCs, DPSCs, WJSCs and BMSCs) were used.

\section{Histological analyses}

Control native human skin (NHS) and HHS kept in vitro (for 1, 2 and 4 weeks) and grafted in vivo (for 15 and $30 \mathrm{~d}$ ) were fixed in $4 \%$ formaldehyde for $24 \mathrm{~h}$ at $4{ }^{\circ} \mathrm{C}$ and embedded in paraffin. $5 \mu \mathrm{m}$-thick tissue sections were stained with haematoxylin-eosin for histological analysis. 5 independent sample replicates were analysed per group.

To evaluate the synthesis of extracellular matrix (ECM) components in the bioengineered dermis, the presence of collagen fibres, glycosaminoglycans (GAGs) and proteoglycans was assessed by histochemistry. First, the presence of collagen fibres was evaluated by picrosirius red histochemistry using Sirius red F3B (Sigma-Aldrich) for $30 \mathrm{~min}$, as previously described (Alfonso-Rodriguez et al., 2014). Fibre organisation was assessed by polarised light microscopy. To identify the presence of glycoproteins in the HHS, the Schiff periodic acid histochemical method (PAS), with Harris's haematoxylin counterstaining for $1 \mathrm{~min}$, was used. Finally, samples were incubated in alcian blue histochemical solution for $30 \mathrm{~min}$ and counterstained with nuclear fast red solution for the detection of extracellular proteoglycans (Alfonso-Rodriguez et al., 2014).

Epithelial layer analysis was performed by immunofluorescence for the epidermal markers cytokeratin 5 (CK5), cytokeratin 10 (CK10) and filaggrin (FGN). Briefly, tissue sections were deparaffinised and rehydrated before antigen retrieval with citrate buffer for $20 \mathrm{~min}$ at $95^{\circ} \mathrm{C}$. Then, samples were prehybridised with normal horse serum (Vector Laboratories) for $1 \mathrm{~h}$ and incubated with prediluted anti-CK5 and anti-CK10 (Master Diagnostica, Granada, Spain) or 1:50 anti-FGN (Abcam) primary

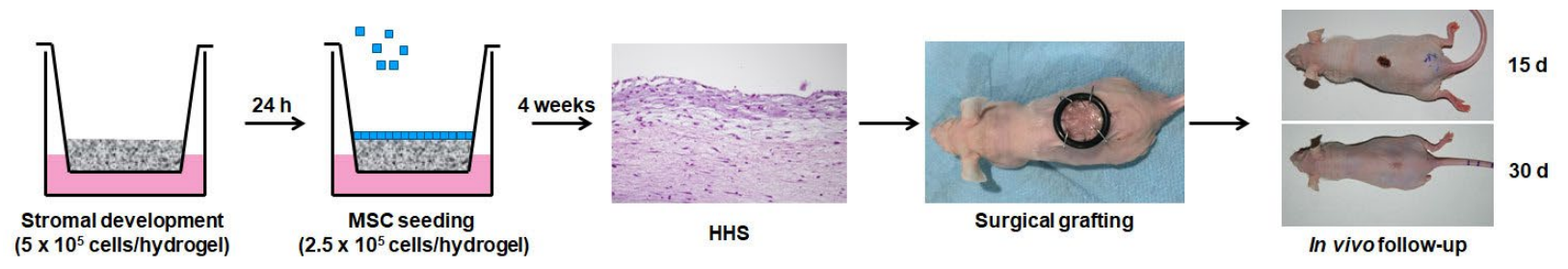

Fig. 1. Generation of heterotypical bioartificial human skin substitutes by tissue engineering and surgical grafting in animal models for in vivo evaluation. 
antibodies overnight at $4{ }^{\circ} \mathrm{C}$. Anti-mouse secondary antibodies conjugated with fluorescein isothiocyanate (FITC; Sigma-Aldrich) were used at a 1:500 dilution. Sections were counterstained with mounting medium containing 4',6-diamidino-2-phenylindole (DAPI; Vector Laboratories).

Toidentify the presence of major histocompatibility complex molecules, routine immunohistochemical methods were used. First, samples were dewaxed and rehydrated and endogenous peroxidase was quenched with $\mathrm{H}_{2} \mathrm{O}_{2}$. Then, tissues were prehybridised and incubated with primary antibodies against type I HLA (HLA I) and type II HLA (HLA II) diluted at 1 : 200 (Santa Cruz Biotech). Positive signal was visualised using 3, 3-diaminobenzidine (DAB; Vector Laboratories) and tissue sections were counterstained for $15 \mathrm{~s}$ with Harris's haematoxylin.

In all cases, light microscopy images were obtained using an Eclipse 90i microscope (Nikon). Results of the histochemical and immunohistochemical analyses were semi-quantitatively analysed as previously described (Garzon et al., 2014; Garzon et al., 2009b). Staining was categorised as strong (+++), mild $(++)$, slight $(+)$ or negative $(-)$. The expression was also stated following the topograpycal location of the signal as basal layer $\left({ }^{a}\right)$, spinosum layer $\left({ }^{b}\right)$, granulosum layer $\left({ }^{c}\right)$, cornified layer $\left({ }^{d}\right)$ or all layers (e). In all cases, average results corresponding to the analysis of 5 replicate samples were obtained.

\section{Preliminary gene expression analysis}

To determine the putative differentiation potential of each MSC type, ADSCs, DPSCs, WJSCs and BMSCs were kept in culture in basal medium (DMEM supplemented with $10 \%$ foetal calf serum and antibiotics-antimycotics) or epithelial induction medium (QC) for $28 \mathrm{~d}$. Then, total RNA was isolated from each cell culture using RNeasy Mini Kit (Qiagen) and retrotranscribed to cDNA using a reverse transcriptase (Superscript II, Life Technologies) and a T7-oligo(dT) primer. Biotinylated cRNA was generated using a T7 RNA polymerase and biotin-11-uridine-5' -triphosphate (Enzo Diagnostics, Farmingdale, NY, USA), chemically fragmented and hybridised to Affymetrix Human Genome U133 plus 2.0 oligonucleotide arrays (Affymetrix Inc., Santa Clara, CA, USA) for $6 \mathrm{~h}$ at $45^{\circ} \mathrm{C} .4$ samples were analysed per group $(n=4)$. Expression levels found for each probe-set in the array were classified as present $(\mathrm{P})$, marginal $(\mathrm{M})$ or absent $(\mathrm{A})$ for each sample by using the Affymetrix Suite software (Affymetrix Inc.). Affymetrix NetAffx Analysis Center (Affymetrix Inc.) was used to identify all genes in the array with a putative epithelial-cell-related function. All probe-sets showing an expression increase after QC induction (for example, an absent gene in cells cultured with basal medium that became present upon QC culturing) were selected for each MSC type. To determine the gene functions associated with

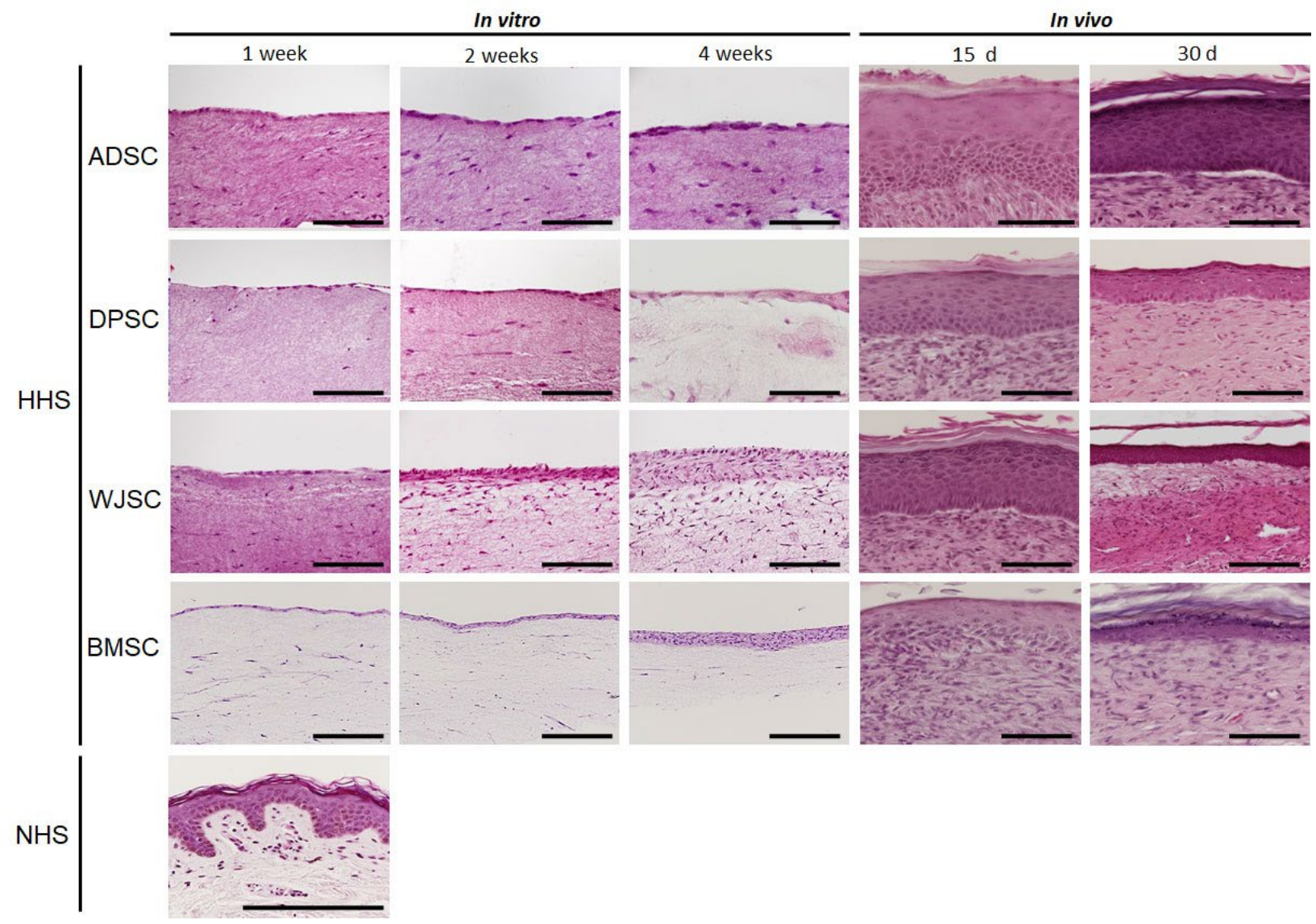

Fig. 2. Haematoxylin and eosin histological analysis of NHS and HHS generated using ADSCs, DPSCs, WJSCs and BMSCs kept in vitro for 1, 2 and 4 weeks and grafted in vivo for 15 and $30 \mathrm{~d}$. Scale bar: $200 \mu \mathrm{m}$. 
selected probe-sets, BiNGO gene ontology analysis (Ghent University, Belgium) was used as previously described (Maere et al., 2005).

\section{Results}

\section{Gene expression analysis}

Preliminary gene expression analysis suggested that QC differentiation medium induced the expression of several genes in the 4 MSC types evaluated (Raw Data file 1). Out of the 54,613 array probe-sets, 4,351 (7.97\% of all probe-sets) became upregulated upon induction in ADSCs, with 172 being identified as epithelial genes. For WJSCs, 3,670 probe-sets (6.72 \%) were upregulated, with 184 corresponding to epithelial genes. When BMSCs were analysed, 2,913 probe-sets (5.33\%) were upregulated, with 103 being identified as epithelial genes. Finally, 2,545 probe-sets (4.66 \%) were upregulated in DPSCs, with 106 corresponding to epithelial genes. BiNGO gene ontology analysis identified 98 gene functions associated with all probe-sets activated in ADSCs, 76 in WJSCs and 23 in BMSCs and DPSCs (Raw Data 2 file). Although most 'GO' gene functions corresponded to unspecific cell components and cell physiology, some of these functions were associated with cell adhesion and cell-cell junctions.

In vitro and in vivo histological analysis

In vitro generation of HHS substitutes using ADSCs, DPSCs, WJSCs and BMSCs allowed for the development of an epithelial-like layer from the first week of culture in all study groups (Fig. 2). HHS generated using transdifferentiated ADSCs and DPSCs were able to form an epithelium-like structure composed of a single cell layer along the 4 weeks of in vitro culture without any sign of terminal differentiation.

Grafting of HHS for the treatment of skin wounds did not generate any signs of inflammation, necrosis or other harmful effects. After $15 \mathrm{~d}$ post-grafting, wound diameter showed an average contraction of $45 \%$ as compared to the original injury for all experimental groups and $61.7 \%$ after $30 \mathrm{~d}$ (Fig. 1). However, after in vivo grafting, both cell populations induced the generation of up to 10 epithelial-like layers after 15 and $30 \mathrm{~d}$. Haematoxylin-eosin histological

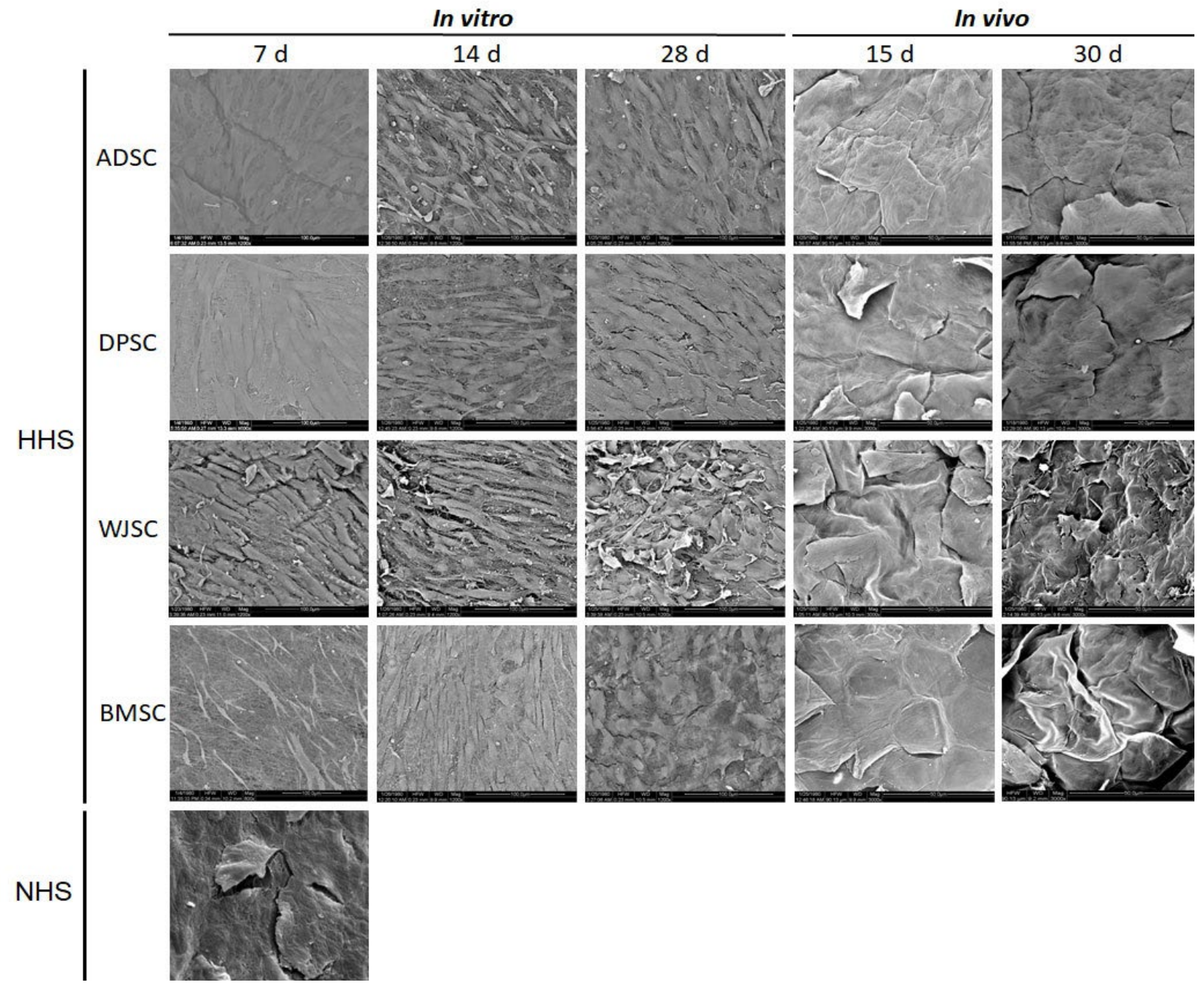

Fig. 3. Analysis of the epithelial surface of NHS and HHS generated using ADSCs, DPSCs, WJSCs and BMSCs kept in vitro for 1, 2 and 4 weeks and grafted in vivo for 15 and $30 \mathrm{~d}$. 
staining revealed the presence of basal, spinosum, granulosum and cornified strata both in ADSCs and DPSCs once grafted in vivo, being similar to NHS. In addition, non-dermal papillae and epithelial rete ridges were identified in vitro or in vivo. When WJSCs and BMSCs were used as epithelial substitutes, a single layer was observed after 1 week in vitro. In contrast, after $14 \mathrm{~d}$, the epithelial-like tissue formed more than 2 layers. The number of formed layers was time-dependent, with the identification of more than 6 layers after $28 \mathrm{~d}$ in both WJSCs and BMSCs, more being formed when WJSCs were used. Strikingly, all cell layers were morphologically similar and no signs of stratum differentiation were found in vitro. After in vivo implantation, epithelial cells showed a high degree of organisation and differentiation in basal, spinosum, granulosum and cornified strata, as in the case of NHS, although rete ridges and dermal papillae were not identified. The analysis of the epithelial surface of the different HHS, as determined by scanning electron microscopy (SEM), demonstrated that the MSCs used as epithelial-like substitute in vitro had the typical spindle-shape, elongated morphology of native MSCs (Fig. 3). However, cells tended to partially change their morphology and acquire a more polygonal shape with time in culture, especially in the case of WJSCs and BMSCs at day 28. Once grafted in vivo, the four MSC types showed a clear morphological change and cells became clearly flat and polygonal, showing keratinisation and desquamation signs, especially after $30 \mathrm{~d}$ of in vivo development.

In vitro and in vivo evaluation of the dermal substitute

The dermal substitute was mainly composed of cellular and extracellular components. A spindle- shape cell population was found in all in vitro HHS substitutes and the cell number tended to increase once grafted in vivo (Fig. 2).

The ECM is mainly composed of fibrillar and nonfibrillar molecules. In terms of fibrillar components, collagen fibres were identified by picrosirius red staining (Fig. 4, Table 1). In vitro development did not show any sign of mature collagen synthesis in ADSC, DPSC, WJSC or BMSC HHS samples. However, in vivo grafting resulted in the expression of collagen fibres, mainly in WJSCs after $15 \mathrm{~d}$ and in DPSCs, WJSCs and BMSCs after $30 \mathrm{~d}$, with similar amount and fibre organisation as compared to NHS. However, ADSCs showed mild expression of collagen from day 15.

Regarding the non-fibrillar components of ECM, GAGs staining by PAS was negative in all in vitro samples. Furthermore, in vivo implantation of HHS using MSCs resulted in mildly positive expression of GAGs at $30 \mathrm{~d}$ in DPSC, WJSC and BMSC HHS and positive signal in ADSC HHS at the basement membrane. Interestingly, the staining signal found in ADSCs corresponding to day 30 was comparable to that of NHS (Fig. 5, Table 1).

Alcian blue staining detected proteoglycans as other important non-fibrillar components of the ECM (Fig. 6, Table 1). In this sense, in vitro development of HHS resulted in a lack of expression of these molecules. Once HHS samples were implanted in an animal model, proteoglycans synthesis reached intermediate levels of expression in ADSCs, DPSCs and WJSCs after $15 \mathrm{~d}$. BMSCs revealed stronger synthesis with similar levels to NHS after $15 \mathrm{~d}$. Moreover, at $30 \mathrm{~d}$ post-implantation, all MSC groups showed high expression of proteoglycans with amounts similar to NHS.
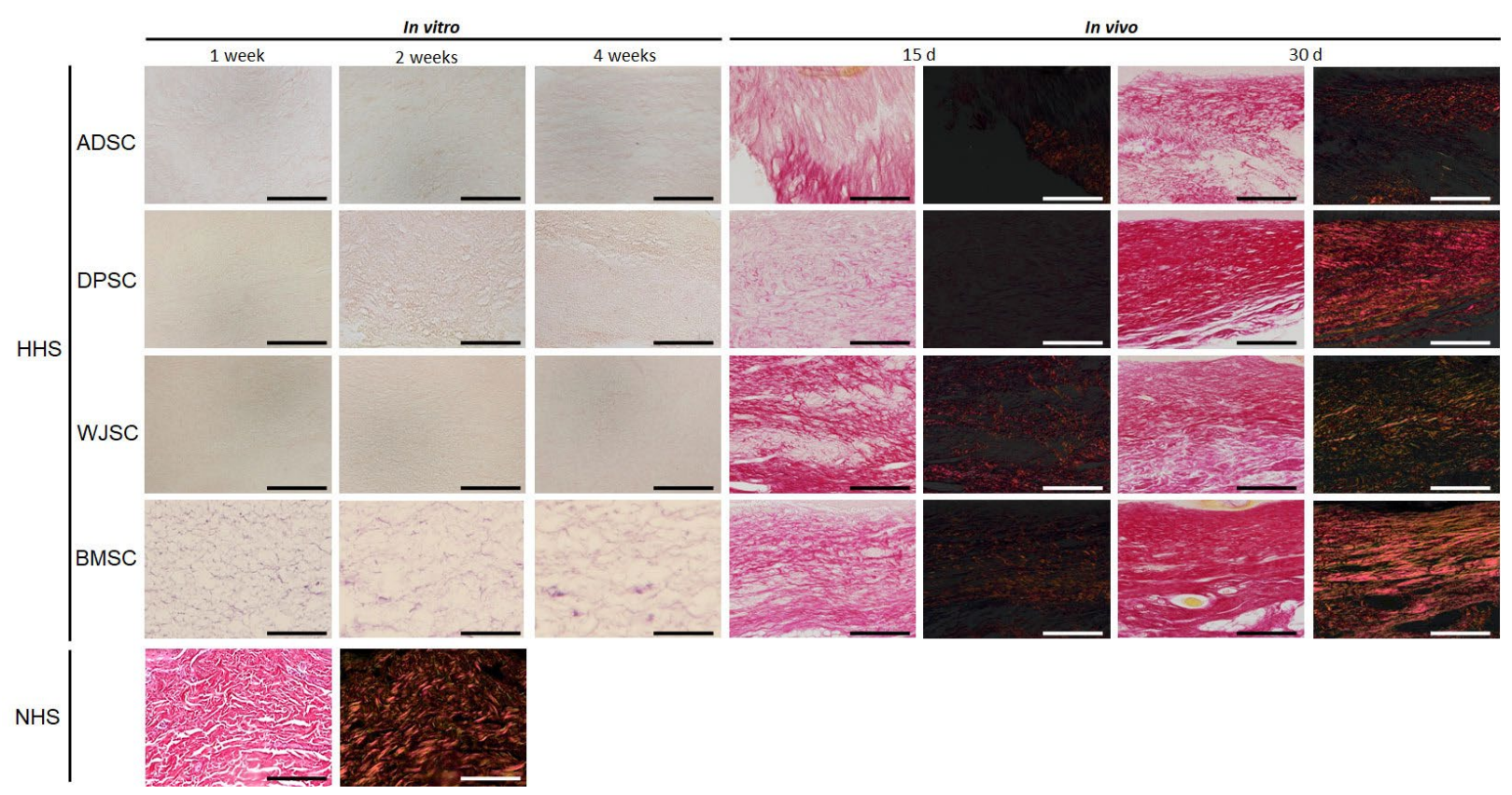

Fig. 4. Picrosirius red histochemical analysis of NHS and HHS generated using ADSCs, DPSCs, WJSCs and BMSCs kept in vitro for 1, 2 and 4 weeks and grafted in vivo for 15 and $30 \mathrm{~d}$. Scale bar: $200 \mu \mathrm{m}$. 
Table 1. Semiquantitative analysis of ECM components, epithelial markers and HLA antigens in native and heterotypical bioengineered human skin. The well-organised collagen fibres of the ECM components are indicated by an asterisk. The staining reaction was categorised in each sample as strong (+++), mild (++), slight (+) or negative (-). For epithelial markers (CK5, CK10 and FGN), the positive expression was stated as basal layer $\left({ }^{a}\right)$, spinosum layer $\left({ }^{b}\right)$, granulosum layer $\left({ }^{c}\right)$, cornified layer $\left({ }^{d}\right)$ or all layers $\left({ }^{e}\right) .{ }^{\S}$ indicates that the expression was mainly detected at basal stratum, but it could be present with lower intensity in other strata.

\begin{tabular}{|c|c|c|c|c|c|c|c|c|}
\hline & & & & & In vitro & & & vo \\
\hline & & NHS & HHS & 1 week & 2 weeks & 4 weeks & $15 \mathrm{~d}$ & $30 \mathrm{~d}$ \\
\hline \multirow{12}{*}{ 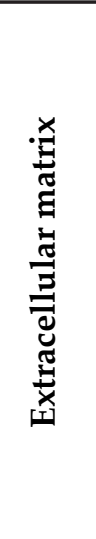 } & \multirow{4}{*}{ Collagen fibres } & \multirow{4}{*}{$+++(*)$} & ADSCs & - & - & - & ++ & ++ \\
\hline & & & DPSCs & - & - & - & + & $+++(*)$ \\
\hline & & & WJSCs & - & - & - & $+++(*)$ & $+++(*)$ \\
\hline & & & BMSCs & - & - & - & $++\left({ }^{*}\right)$ & $+++(*)$ \\
\hline & \multirow{4}{*}{ GAG } & \multirow{4}{*}{++} & ADSCs & - & - & - & - & ++ \\
\hline & & & DPSCs & - & - & - & - & + \\
\hline & & & WJSCs & - & - & - & - & + \\
\hline & & & BMSCs & - & - & - & - & + \\
\hline & \multirow{4}{*}{ Proteoglycans } & \multirow{4}{*}{+++} & ADSCs & - & - & - & ++ & +++ \\
\hline & & & DPSCs & - & - & - & ++ & +++ \\
\hline & & & WJSCs & - & - & - & ++ & +++ \\
\hline & & & BMSCs & - & - & - & +++ & +++ \\
\hline \multirow{12}{*}{ 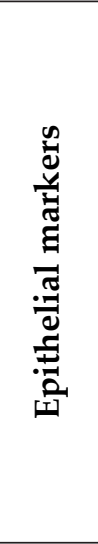 } & \multirow{4}{*}{ CK5 } & \multirow{4}{*}{$+++^{a, \S}$} & ADSCs & - & - & - & $++^{\mathrm{e}}$ & $++^{\mathrm{e}}$ \\
\hline & & & DPSCs & - & - & - & $++^{\mathrm{e}}$ & $++^{\mathrm{e}}$ \\
\hline & & & WJSCs & - & - & $+^{\mathrm{e}}$ & $++^{a \S}$ & $++^{a \S}$ \\
\hline & & & BMSCs & $+^{e}$ & $+^{\mathrm{e}}$ & $+^{\mathrm{e}}$ & $++^{a \S}$ & $++^{a \S}$ \\
\hline & \multirow{4}{*}{ CK10 } & \multirow{4}{*}{$+++^{c, d}$} & ADSCs & - & - & - & - & $+^{c}$ \\
\hline & & & DPSCs & - & - & - & - & $+^{c}$ \\
\hline & & & WJSCs & - & - & $+^{\mathrm{e}}$ & $++^{c, d}$ & $++^{c, d}$ \\
\hline & & & BMSCs & - & $++^{\mathrm{e}}$ & $+^{\mathrm{e}}$ & - & $++^{c, d}$ \\
\hline & \multirow{4}{*}{ Filaggrin } & \multirow{4}{*}{$+++^{d}$} & ADSCs & - & - & - & $++^{c, d}$ & $++^{\mathrm{c}, \mathrm{d}}$ \\
\hline & & & DPSCs & - & - & - & $++^{c, d}$ & $++^{c, d}$ \\
\hline & & & WJSCs & - & - & - & $++^{c, d}$ & $+++{ }^{\mathrm{d}}$ \\
\hline & & & BMSCs & - & - & - & - & $++^{c, d}$ \\
\hline \multirow{8}{*}{ 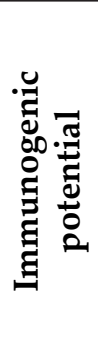 } & \multirow{4}{*}{ HLA I } & \multirow{4}{*}{+++} & ADSCs & - & - & - & - & - \\
\hline & & & DPSCs & - & - & - & - & - \\
\hline & & & WJSCs & - & - & - & - & - \\
\hline & & & BMSCs & - & + & + & - & - \\
\hline & \multirow{4}{*}{ HLA II } & \multirow{4}{*}{++} & ADSCs & - & - & - & - & - \\
\hline & & & DPSCs & - & - & - & - & - \\
\hline & & & WJSCs & - & - & - & - & - \\
\hline & & & BMSCs & - & - & - & + & + \\
\hline
\end{tabular}

In vitro and in vivo expression of skin epithelial markers

CK5 expression was negative in vitro in ADSCs and DPSCs and positive in all layers after in vivo implantation. Moreover, WJSCs were slightly positive for CK5 expression after 4 weeks of in vitro development and signal notably increased after 15 and $30 \mathrm{~d}$ of implantation, resembling the expression pattern of native human skin - with positive expression mainly in the basal layer (Fig. 7, Table 1). Finally, BMSCs showed a slight expression of CK5 at 1,2 and 4 weeks in all layers in vitro and mimicked the expression pattern of native human skin in vivo. The expression of CK10 in HHS samples was negative for ADSCs and DPSCs after 4 weeks of in vitro culture. Interestingly, a slight expression of CK10 was detected in all layers of BMSC samples after 2 weeks of in vitro development and after 4 weeks in vivo. Similar expression levels were achieved in WJSCs after 4 weeks (Fig. 8, Table 1). Once grafted in vivo, WJSCs were the first MSC population able to generate epithelium-like cells expressing mild levels of CK10 in the cornified and granulosum layers $15 \mathrm{~d}$ post-implantation, which was maintained up to $30 \mathrm{~d}$. At the end of the study, BMSCs and DPSCs showed a similar mild expression pattern of CK10, whereas ADSCs revealed a lower CK10 signal, confined to the granulosum layer.

According to FGN expression, in vitro analysis did not show any sign of epithelial maturation (Fig. 


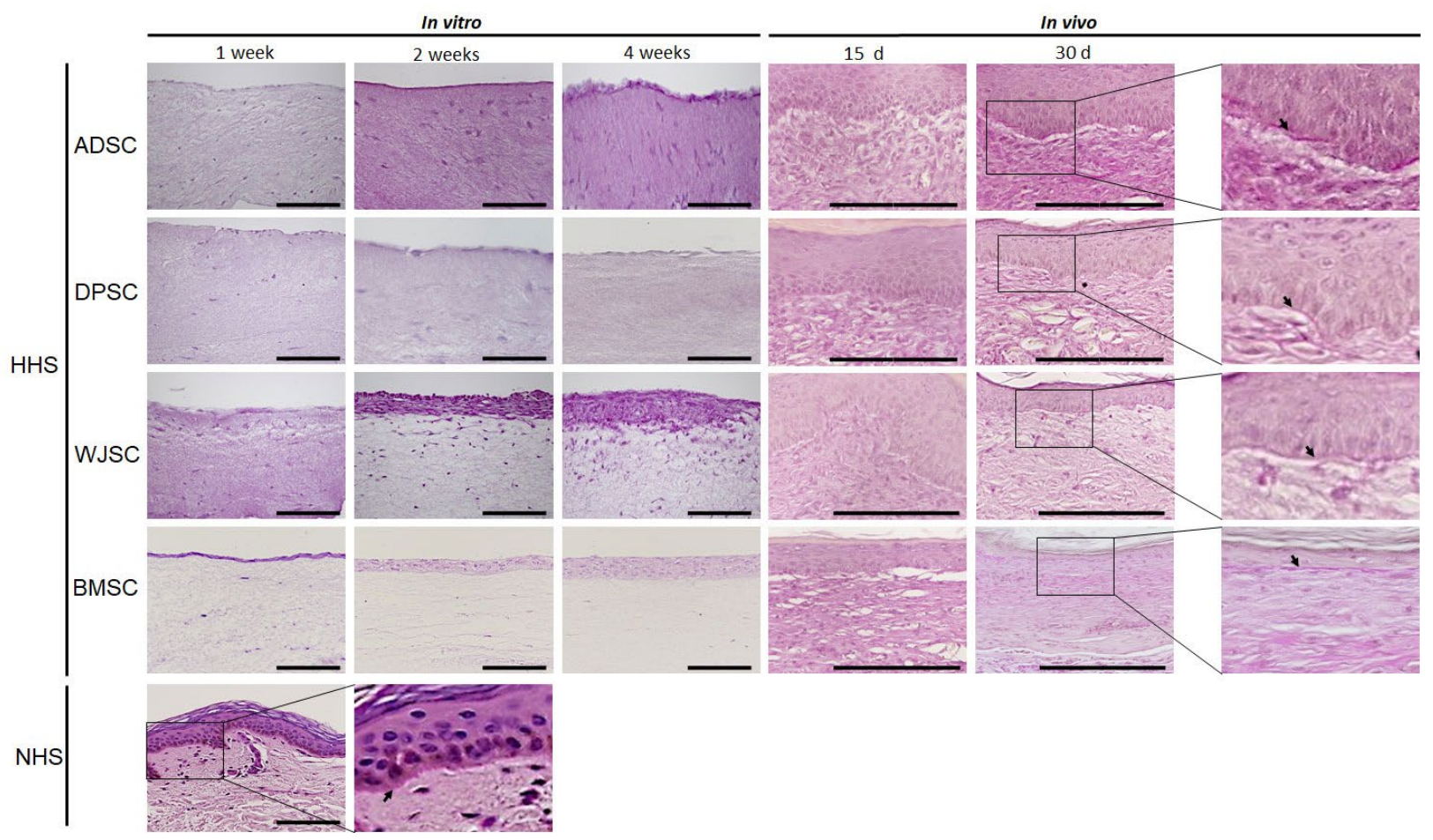

Fig. 5. PAS histochemical analysis of NHS and HHS generated using ADSCs, DPSCs, WJSCs and BMSCs kept in vitro for 1, 2 and 4 weeks and grafted in vivo for 15 and $30 \mathrm{~d}$. Scale bar: $200 \mu \mathrm{m}$. Black arrows point to GAGs in the basement membrane.

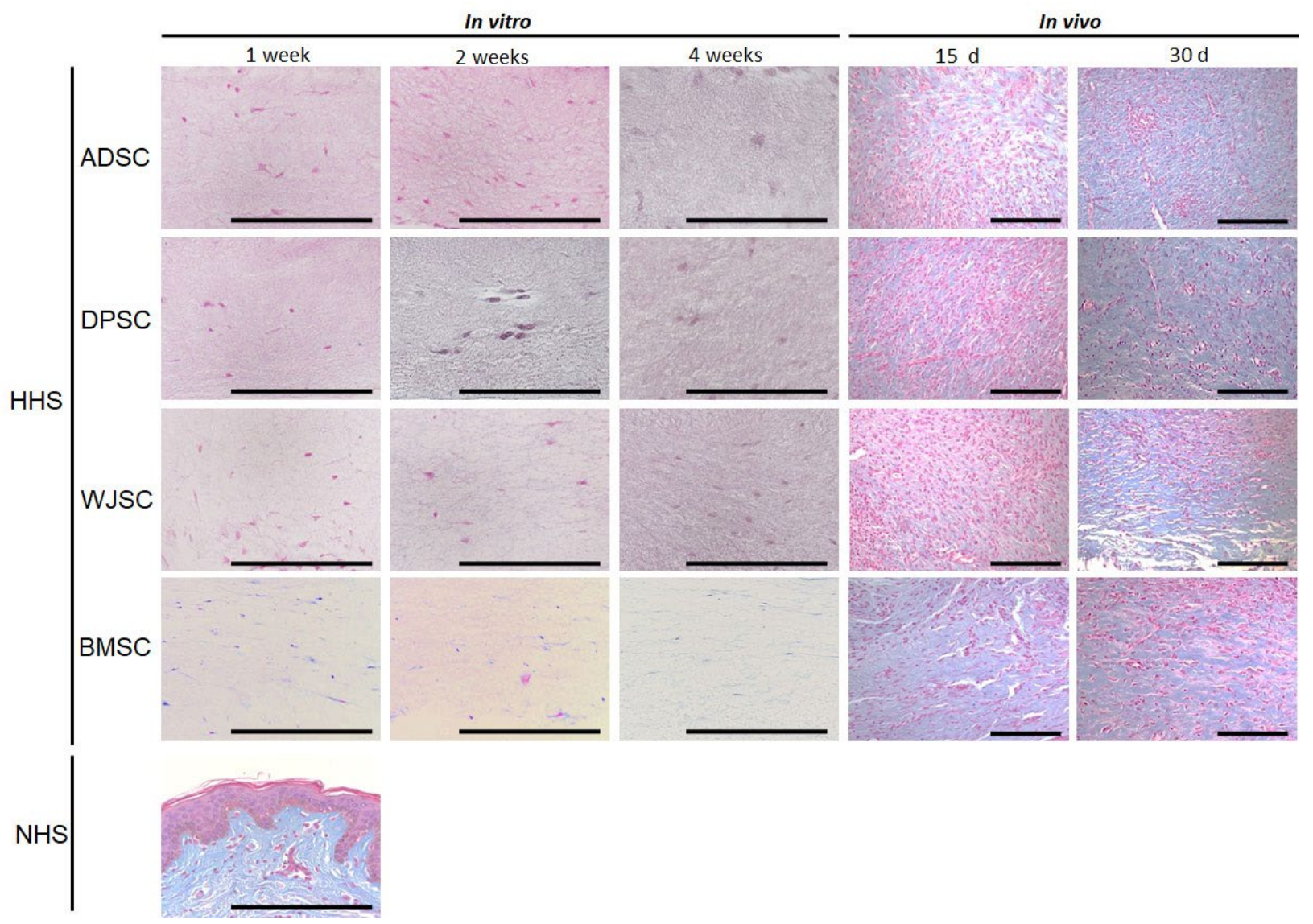

Fig. 6. Alcian blue histochemical analysis of NHS and HHS generated using ADSCs, DPSCs, WJSCs and BMSCs kept in vitro for 1, 2 and 4 weeks and grafted in vivo for 15 and $30 \mathrm{~d}$. Scale bar: $200 \mu \mathrm{m}$. 


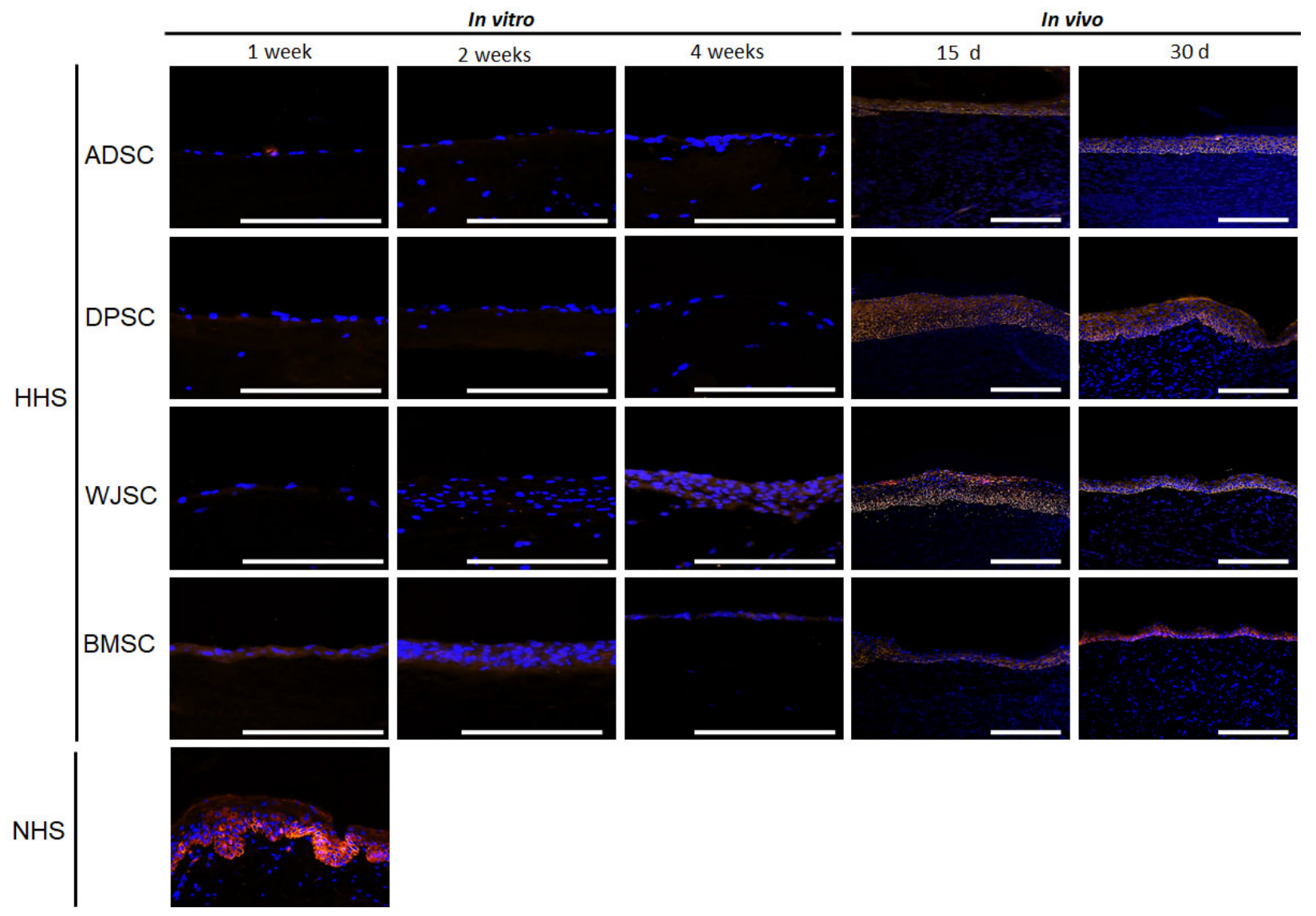

Fig. 7. Immunofluorescent analysis of CK5 in NHS and HHS generated using ADSCs, DPSCs, WJSCs and BMSCs kept in vitro for 1, 2 and 4 weeks and grafted in vivo for 15 and $30 \mathrm{~d}$. Scale bar: $200 \mu \mathrm{m}$.

9, Table 1). Nonetheless, samples corresponding to ADSCs, DPSCs and WJSCs showed a slight FGN expression in cornified and granulosum layers after $15 \mathrm{~d}$ of in vivo implantation and all samples had a mild expression after $30 \mathrm{~d}$ of in vivo grafting, except for WJSCs, which reached similar expression at the cornified layer mimicking NHS.

\section{In vitro and in vivo immunogenical evaluation of} HHS samples

The immunogenical potential of transdifferentiated MSCs was evaluated by the detection of HLA complex molecules. MSCs used to generate HHS models revealed low expression of HLA I molecules evaluated by immunohistochemistry in BMSCs and a lack of HLA II in all MSC groups in vitro. Once grafted, transdifferentiated MSCs were negative in all groups both at 15 and $30 \mathrm{~d}$ for HLA I. BMSCs showed a mild expression of HLA II after 15 and $30 \mathrm{~d}$ post-implantation (Fig. 10 and 11, Table 1).

\section{Discussion}

The skin is the largest organ of the human body. It serves as an effective barrier between the organism and the environment and is involved in the regulation of body temperature and fluid loss (Proksch et al.,
2008). Among the main conditions severely affecting the human skin, burns are serious therapeutical situations for which a fully valid management approach is not clinically available. In fact, treatment of deep burn-wounds is based on the use of autografts, which are not available in cases where large areas of skin are affected. Recently, tissue engineering has emerged as a therapeutic alternative, allowing the generation of autologous full-thickness skin substitutes for the treatment of deep burnwounds and showing promising results (Llames et al., 2004). Development of heterotypical artificial skin models would contribute to overcome the drawbacks associated with the generation of bioengineered skin.

The use of MSCs as alternative cell sources offers several potential advantages such as availability, proliferation and differentiation capability with low immunogenic potential (Koppula et al., 2009; Weiss et al., 2008). The lack of immunological reaction makes these cells excellent candidates for cellular therapy in an allogeneic setting (Le Blanc and Ringden, 2005). However, a comparative study focussed on the differentiation potential of the four main sources of MSCs into skin epithelium has not been carried out to date. The present study approach was to determine the capability of each of the four MSC types to be induced using a specific epithelial conditioning medium in two-dimensional (2D) culture systems. 


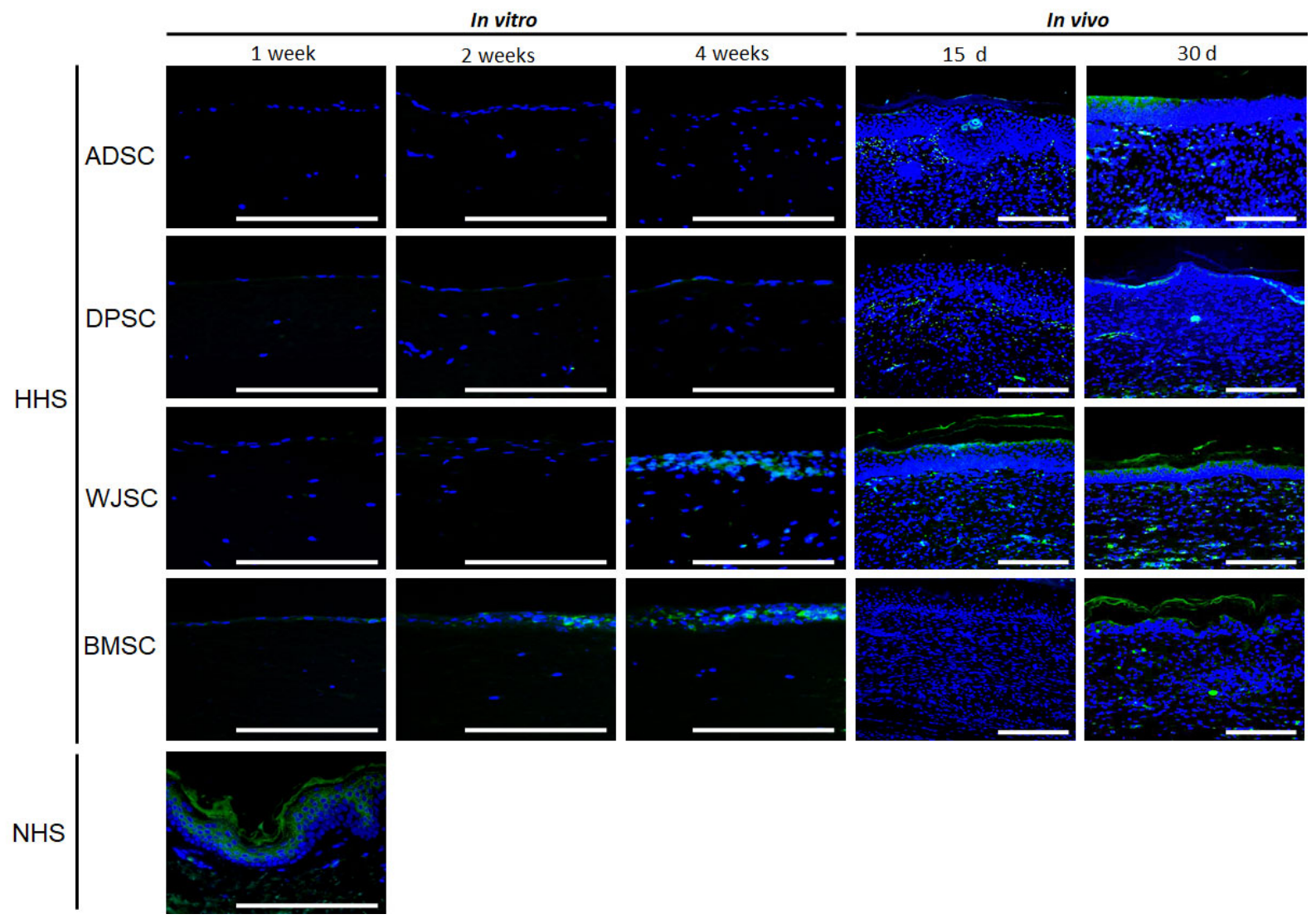

Fig. 8. Immunofluorescent analysis of CK10 in NHS and HHS generated using ADSCs, DPSCs, WJSCs and BMSCs kept in vitro for 1, 2 and 4 weeks and grafted in vivo for 15 and $30 \mathrm{~d}$. Scale bar: $200 \mu \mathrm{m}$.

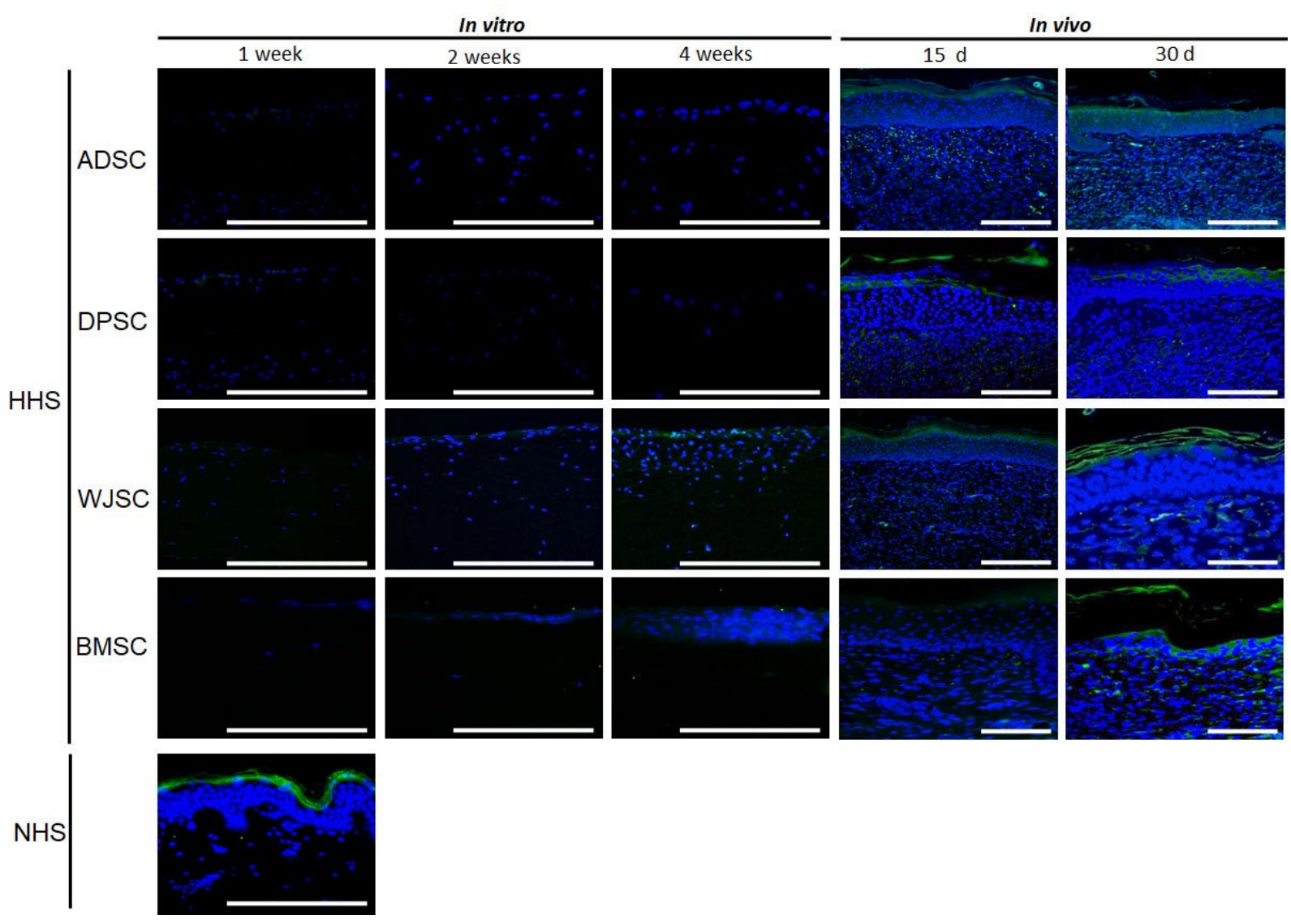

Fig. 9. Immunofluorescent analysis of FGN in NHS and HHS generated using ADSCs, DPSCs, WJSCs and BMSCs kept in vitro for 1, 2 and 4 weeks and grafted in vivo for 15 and $\mathbf{3 0} \mathrm{d}$. Scale bar: $200 \mu \mathrm{m}$. 
Results showed a small number of induced genes. ADSCs and WJSCs showed larger percentages of induced genes. However, BMSCs and DPSCs were able to induce a series of genes with a putative role in epithelial cell function, such as cell adhesion. These results supported the use of the four MSC types in tissue engineering, given their epithelial differentiation capability, as previously demonstrated (Zhang et al., 2012). In the present work, novel models of bioengineered skin generated by using four MSC types were described. In agreement with previous reports, suggesting that heterotypical bioengineered tissues have low levels of differentiation while kept in vitro (Garzon et al., 2013; Garzon et al., 2009a), in vitro tissues had very few cell layers on top of the dermis substitute - although the number of cell layers tended to increase with time - and a complete absence of differentiation markers, such as rete ridges and chorial papillae or keratinisation.

Expression of CK is one of the main features of human epidermal cells. For this reason, the first CK analysed was CK5, which is paired with CK14 and is a marker of basal proliferative keratinocytes that act as epithelial stem cells (Kim et al., 2002). Results showed that WJSCs and BMSCs were able to express small amounts of this marker under in vitro conditions, suggesting that these cell types could respond to epithelial inductive medium more efficiently than ADSCs and DPSCs. However, the in vivo setting was able to induce the expression of
CK5 in all samples, but the expression pattern tended to resemble the preferentially basal expression of native skin only in the two cell types that showed the highest differentiation potential in vitro, WJSCs and BMSCs. On the other hand, HHS generated using WJSCs and BMSCs showed mild expression of CK10 in most epithelial-like cells. The slight expression of CK10 under in vitro conditions could be linked to an early epithelial differentiation stage. However, when tissue samples were implanted in vivo, differentiation was enhanced and stratification organisation was more evident. The proper set-up of basal cells may enhance proliferation and cell differentiation into epithelial-like tissue. An interesting phenomenon was that BMSCs showed slight CK10 expression in vitro, but this expression was initially negative in vivo and became positive at $30 \mathrm{~d}$. This finding may be explained as an adaptive process of the cells, which could partially lose their original orientation in vivo and, thus, minimise their expression profile until the epithelium became fully differentiated. These results, related to the in vitro differentiation potential of WJSCs and BMSCs, were in agreement with previous work demonstrating their keratinocytic differentiation capability (Garzon et al., 2013) and with the fact that ADSCs and DPSCs have not yet been differentiated into skin keratinocytes - although reports have suggested that these cell types may have epithelial differentiation capability in the presence of inductive medium (Baer et al., 2013; Dogan et al.,

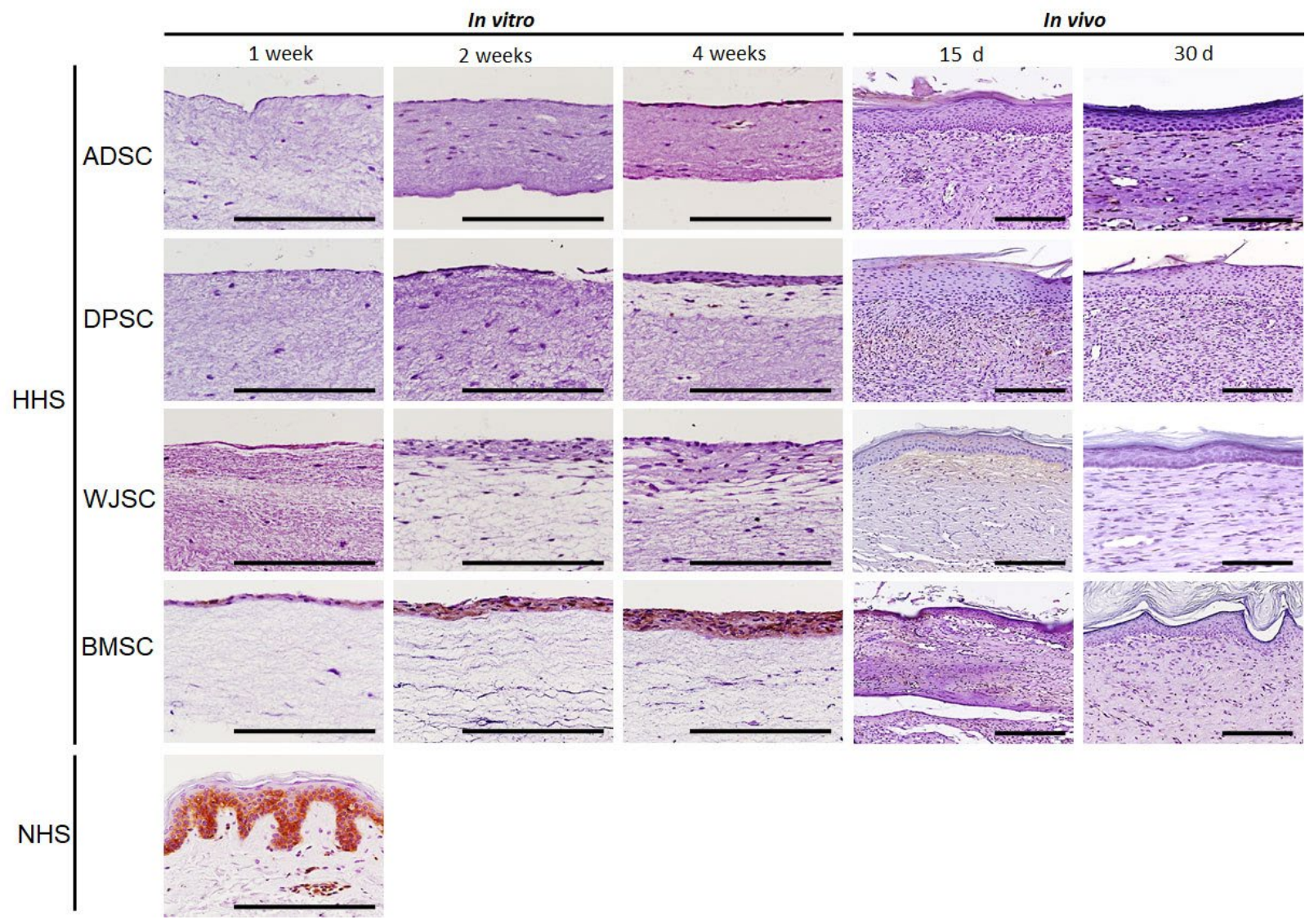

Fig. 10. Immunohistochemistry analysis of HLA I in NHS and HHS generated using ADSCs, DPSCs, WJSCs and BMSCs kept in vitro for 1, 2 and 4 weeks and grafted in vivo for 15 and $30 \mathrm{~d}$. Scale bar: $200 \mu \mathrm{m}$. 
2015). In the present study, both WJSCs and BMSCs were able to develop a larger number of cell layers at the in vitro stage, which coincided with the early cytokeratin expression. Therefore, the use of a combined trans-differentiation protocol based on epithelial conditioning medium, 3D systems with dermal cells supporting epithelial-mesenchymal interaction and air-liquid culture technique could partially induce in vitro epidermal differentiation of some of the studied MSC types but failed to achieve terminal differentiation.

In vivo grafting was performed by using a plastic ring standardised model (Fang and Mustoe, 2008; Galiano et al., 2004) to minimise and control wound contraction. Previous studies have described contraction in mice as a common physiological phenomenon after skin grafting. Park et al. (2014) compared the use of splinted versus non-splinted models and demonstrated that the wound generated in the skin of the animal tends to fully shrink and contract after $11 \mathrm{~d}$ in non-splinted models, whereas splinted models reduce the contraction rate to near $60 \%$ after $11 \mathrm{~d}$ (Gebremeskel et al., 2018; Park et al., 2014). In the present study, the wound contraction percentage reached $61.7 \%$ after $30 \mathrm{~d}$, suggesting a reduction of the wound contraction that may improve re-epithelisation with the grafted tissue. These results are in accordance with a study reporting that use of silicone splints around dorsal wounds may attenuate contraction but that the final graft size is typically around 40-50\% (Galiano et al., 2004).

Once grafted in vivo, MSCs were subjected to additional differentiation signals depending on the local and systemic inductive factors generated by the host. This resulted in higher differentiation in all cases, with the formation of terminally differentiated epithelial cell layers and other differentiation markers. Previous reports have demonstrated that the in vivo environment is necessary for the cells to fully develop and differentiate, which does not occur in vitro (Garzon et al., 2009a; Garzon et al., 2013). One of the challenges of bioartificial tissues grafted in immunodeficient animals is demonstrating the presence of the human cells in the graft and determining the fate of the implanted cells. In the present work, human-specific antibodies were used to demonstrate that cells in the regenerated skin area were of human nature. Future studies should analyse cell migration and stability in vivo by using high-definition cell-tracking techniques (Bulte and Daldrup-Link, 2018).

The in vitro analysis of the dermal substitute showed a complete absence of the fibrillar and nonfibrillar ECM components analysed, which tended to appear in vivo. In general, the artificial dermis grafted in vivo was able to synthesise and generate abundant amounts of collagen fibres and reached the levels of the control except for ADSCs, suggesting that the type

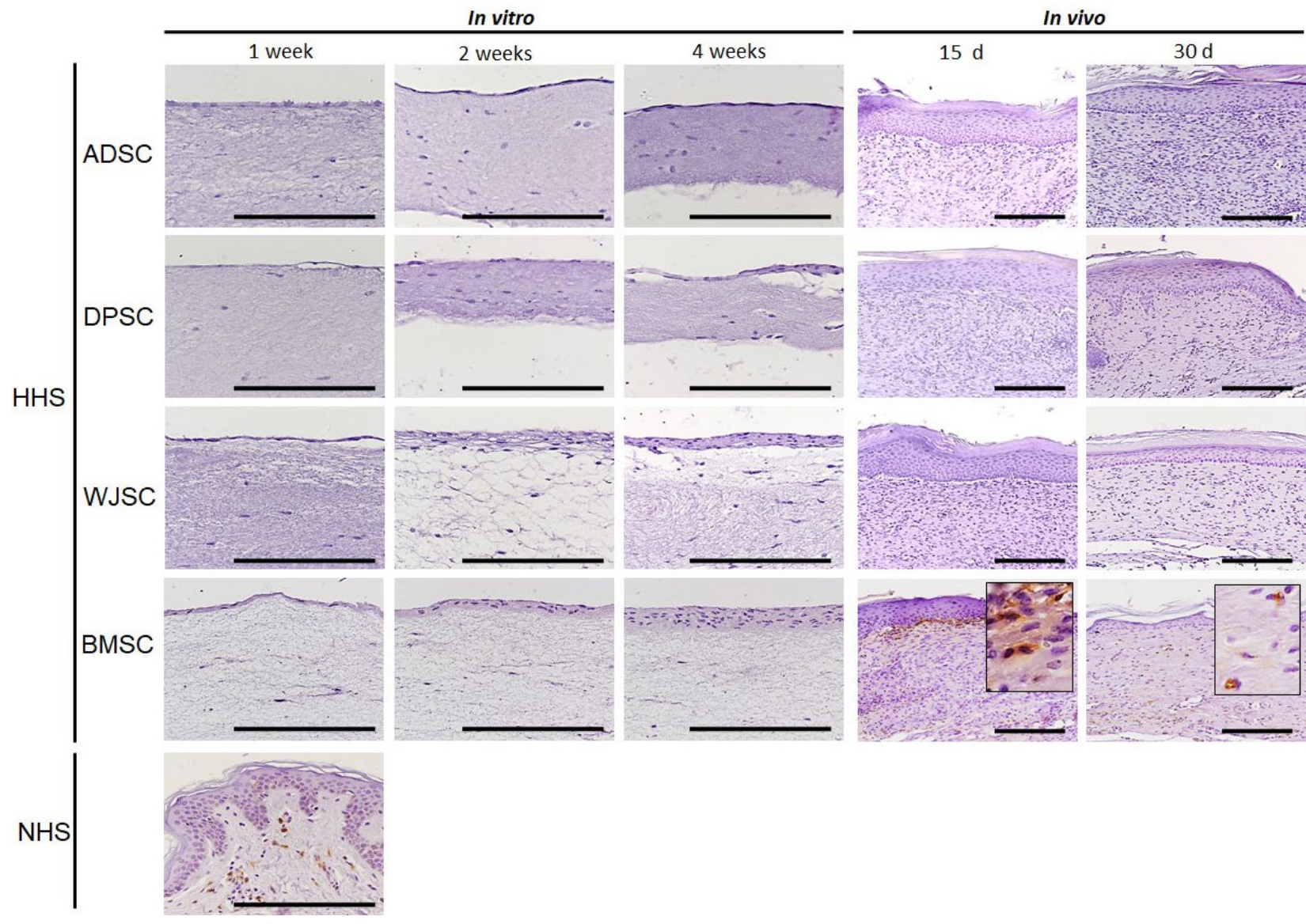

Fig. 11. Immunohistochemistry analysis of HLA II in NHS and HHS generated using ADSCs, DPSCs, WJSCs and BMSCs kept in vitro for 1, 2 and 4 weeks and grafted in vivo for 15 and $30 \mathrm{~d}$. Scale bar: $200 \mu \mathrm{m}$. 
of MSCs used as epithelial substitute may influence the biosynthetic activity of dermal fibroblasts. The presence of collagen fibres is very important to keep the biomechanical properties of the human skin (Aziz et al., 2016) and its presence in the dermal substitute could favour the adequate physiology and mechanical behaviour of the artificial skin. In this regard, the fibrin-agarose bioartificial human tissue substitutes share some biomechanical similarities [G' modulus ranging between 30 and $70 \mathrm{~Pa}$ and $\mathrm{G}^{\prime \prime}$ between 40 and $50 \mathrm{~Pa}$ (Rodriguez et al., 2012)] with native human tissues, although their biomechanical properties are not completely biomimetic to control tissues.

Regarding the non-fibrillar ECM components of the dermal substitute, results showed that the four types of HHC were able to synthesise GAGs, although only ADSCs were able to reach the expression levels found in the control tissues. However, proteoglycans were very abundant in the four MSC types after $30 \mathrm{~d}$ of development, suggesting that this important dermal component was easily generated by the dermal fibroblasts independently of the type of epithelial substitute found on top. Previous work showed that GAGs and proteoglycans are important components of the skin ECM that may facilitate wound healing, cell adhesion, migration, proliferation, metabolism, differentiation, survival and growth factor activity (Ghatak et al., 2015). Therefore, their presence in the bioengineered skin should be a requisite for these tissues to be clinically useful and previous fibrinagarose human bioartificial skin models display high expression of these components in vivo (MartinPiedra et al., 2017).

Results of the epithelial substitute showed that the highest epithelial differentiation potential corresponded to WJSCs and BMSCs according to CK10 expression and WJSCs according to FGN. Along with the larger number of cell layers in WJSCbased HHS, these findings would confirm previous results showing the skin-epithelium differentiation potential of WJSCs (Garzon et al., 2013). In contrast with the other three MSC types studied, WJSCs were obtained from new-born umbilical cords. This perinatal cell source could retain some of the proliferation and differentiation capabilities of embryonic cells, which could explain their potential in tissue regeneration. WJSCs are easily accessible and have been extensively used in tissue engineering and regenerative medicine without the risk of tumorigenesis (Joerger-Messerli et al., 2016). However, the other three MSC types also displayed differentiation potential as epithelial markers, as determined by CK10 and FGN expression analysis, and showed high expression of proteoglycans and collagen (especially DPSCs and BMSCs). Future works should determine if these four MSC types may have the potential to fully differentiate into skin epidermis by using other inductive factors or clues, other in vivo models or longer follow-up periods.
One possible issue related to the use of MSCs differentiated towards human epithelial keratinocytes is the possibility that immunopriviliged undifferentiated MSCs (Weiss et al., 2008) might acquire immunogenicity under certain conditions, including epidermal differentiation. In fact, upregulation of major histocompatibility complex (MHC)-II antigens is detected after gamma-interferon induction in MSC cultures, which could point towards this possibility (Le Blanc and Ringden, 2005). In the present work, the four analysed MSC types were initially negative for several HLA I and HLA II markers in the HHS models. However, preliminary epithelial differentiation found in BMSCHHS kept in vitro for 2 and 4 weeks (as determined by CK10 immunostaining) coincided with a slight expression of HLA I antigens. Nevertheless, in vivo grafting resulted in a complete absence of HLA I signal in all HHS types, although HLA II became slightly positive in BMSC-HHS after 15 and $30 \mathrm{~d}$ of in vivo development. The transient expression of HLA I in BMSCs kept in vitro remains intriguing and future studies should be performed to elucidate this issue. One important concern is the possibility that HHS cells could express HLA markers after full differentiation, as previously suggested for bone and cartilage tissue substitutes (Lee et al., 2012; Lohan et al., 2014; Lohan et al., 2017). The lack of information related to HLA expression on MSCs differentiated towards epithelial cell lineages makes necessary to perform future studies using longer follow-up times.

Altogether, these results confirm the absence of immunogenic HLA markers in bioengineered human substitutes generated using ADSCs, DPSCs and WJSCs. Although the epithelial layer was differentiated and would support the future clinical use of these substitutes, BMSC-based HHS could become immunogenic for HLA II upon induction. For this reason, the preferential use of HHS based on ADSCs, DPSCs and WJSCs instead of BMSCs would be recommendable. Therefore, these results would support the use of these types of MSCs for the generation of heterotypical models of human skin, but also other bioengineered tissues or organs such as human cornea and oral mucosa.

For the clinical transference of these bioengineered skin substitutes, several steps should be achieved, including exhaustive preclinical quality control analyses fulfilling the requirements of the European Medicines Agency.

\section{Conclusions}

Results demonstrated the partial epithelial differentiation capability of ADSCs, DPSCs, WJSCs and BMSCs, which could be used for the generation of bioengineered human skin substitutes with potential clinical usefulness. However, WJSCs demonstrated the highest differentiation capability and lack of HLA 
I and II expression upon induction. Therefore, WJSCs could be used for the generation of human skin substitutes. However, future studies should assess the functional properties of the skin regenerated by these substitutes and its long-term differentiation potential.

\section{Acknowledgements}

The study was supported by the Spanish Plan Nacional de Investigación Científica, Desarrollo e Innovación Tecnológica $(\mathrm{I}+\mathrm{D}+\mathrm{I})$ from the Spanish Ministry of Economy and Competitiveness (Instituto de Salud Carlos III), FIS PI15/2048 (co-financed by ERDF-FEDER, European Union), award number AC17/00013 (NanoGSkin) by ISCIII thorough AES 2017 and within the EuroNanoMed framework and PE-0393-2018 from FIBAO foundation, Granada, Spain. The authors thank Amalia de la Rosa and Concha López and the Experimental Unit of the Virgen de las Nieves University Hospital for their support with the surgical procedures and animal experimentation.

The authors have no conflict of interest to declare.

\section{References}

Alfonso-Rodriguez CA, Garzon I, Garrido-Gomez J, Oliveira AC, Martin-Piedra MA, Scionti G, Carriel V, Hernandez-Cortes P, Campos A, Alaminos M (2014) Identification of histological patterns in clinically affected and unaffected palm regions in dupuytren's disease. PLoS One 9: e112457. DOI: 10.1371/journal.pone.0112457.

Alfonso-Rodriguez CA, Gonzalez-Andrades E, Jaimes-Parra BD, Fernandez-Valades R, Campos A, Sanchez-Quevedo MC, Alaminos M, Garzon I (2015) Ex vivo and in vivo modulatory effects of umbilical cord Wharton's jelly stem cells on human oral mucosa stroma substitutes. Histol Histopathol 30: 1321-1332.

Aziz J, Shezali H, Radzi Z, Yahya NA, Abu Kassim NH, Czernuszka J, Rahman MT (2016) Molecular mechanisms of stress-responsive changes in collagen and elastin networks in skin. Skin Pharmacol Physiol 29: 190-203.

Baer PC, Doring C, Hansmann ML, Schubert R, Geiger H (2013) New insights into epithelial differentiation of human adipose-derived stem cells. J Tissue Eng Regen Med 7: 271-278.

Beaudoin Cloutier C, Goyer B, Perron C, Guignard R, Larouche D, Moulin VJ, Germain L, Gauvin R, Auger FA (2017) In vivo evaluation and imaging of a bilayered self-assembled skin substitute using a decellularized dermal matrix grafted on mice. Tissue Eng Part A 23: 313-322.

Bhardwaj N, Chouhan D, Mandal BB (2017) Tissue engineered skin and wound healing: current strategies and future directions. Curr Pharm Des 23: 3455-3482.

Bhowmick S, Rother S, Zimmermann H, Lee PS, Moeller S, Schnabelrauch M, Koul V, Jordan R, Hintze V, Scharnweber D (2017) Biomimetic electrospun scaffolds from main extracellular matrix components for skin tissue engineering application - the role of chondroitin sulfate and sulfated hyaluronan. Mater Sci Eng C Mater Biol Appl 79: 15-22.

Boa O, Cloutier CB, Genest H, Labbe R, Rodrigue B, Soucy J, Roy M, Arsenault F, Ospina CE, Dube N, Rochon MH, Larouche D, Moulin VJ, Germain L, Auger FA (2013) Prospective study on the treatment of lower-extremity chronic venous and mixed ulcers using tissue-engineered skin substitute made by the self-assembly approach. Adv Skin Wound Care 26: 400-409.

Boyce ST, Kagan RJ, Greenhalgh DG, Warner P, Yakuboff KP, Palmieri T, Warden GD (2006) Cultured skin substitutes reduce requirements for harvesting of skin autograft for closure of excised, full-thickness burns. J Trauma 60: 821-829.

Boyce ST, Kagan RJ, Meyer NA, Yakuboff KP, Warden GD (1999) The 1999 clinical research award. Cultured skin substitutes combined with integra artificial skin to replace native skin autograft and allograft for the closure of excised full-thickness burns. J Burn Care Rehabil 20: 453-461.

Boyce ST, Simpson PS, Rieman MT, Warner PM, Yakuboff KP, Bailey JK, Nelson JK, Fowler LA, Kagan RJ (2017) Randomized, paired-site comparison of autologous engineered skin substitutes and splitthickness skin graft for closure of extensive, fullthickness burns. J Burn Care Res 38: 61-70.

Bulte JWM, Daldrup-Link HE (2018) Clinical tracking of cell transfer and cell transplantation: trials and tribulations. Radiology 289: 604-615.

Casiraghi F, Azzollini N, Cassis P, Imberti B, Morigi M, Cugini D, Cavinato RA, Todeschini M, Solini S, Sonzogni A, Perico N, Remuzzi G, Noris M (2008) Pretransplant infusion of mesenchymal stem cells prolongs the survival of a semiallogeneic heart transplant through the generation of regulatory $t$ cells. J Immunol 181: 3933-3946.

Castro-Manrreza ME, Montesinos JJ (2015) Immunoregulation by mesenchymal stem cells: biological aspects and clinical applications. J Immunol Res 2015: 394917. DOI: 10.1155/2015/394917.

Cejka C, Cejkova J, Trosan P, Zajicova A, Sykova E, Holan V (2016) Transfer of mesenchymal stem cells and cyclosporine a on alkali-injured rabbit cornea using nanofiber scaffolds strongly reduces corneal neovascularization and scar formation. Histol Histopathol 31: 969-980.

Dogan A, Demirci S, Sahin F (2015) In vitro differentiation of human tooth germ stem cells into endothelial- and epithelial-like cells. Cell Biol Int 39: 94-103.

Dominici M, Le Blanc K, Mueller I, SlaperCortenbach I, Marini F, Krause D, Deans R, Keating 
A, Prockop D, Horwitz E (2006) Minimal criteria for defining multipotent mesenchymal stromal cells. The international society for cellular therapy position statement. Cytotherapy 8: 315-317.

Dori I, Petrakis S, Giannakopoulou A, Bekiari C, Grivas I, Siska EK, Koliakos G, Papadopoulos GC (2017) Seven days post-injury fate and effects of genetically labelled adipose-derived mesenchymal cells on a rat traumatic brain injury experimental model. Histol Histopathol 32: 1041-1055.

Fang RC, Mustoe TA (2008) Animal models of wound healing: utility in transgenic mice. J Biomater Sci Polym Ed 19: 989-1005.

Forouzandeh F, Jalili RB, Hartwell RV, Allan SE, Boyce S, Supp D, Ghahary A (2010) Local expression of indoleamine 2,3-dioxygenase suppresses T-cellmediated rejection of an engineered bilayer skin substitute. Wound Repair Regen 18: 614-623.

Friedenstein AJ, Gorskaja JF, Kulagina NN (1976) Fibroblast precursors in normal and irradiated mouse hematopoietic organs. Exp Hematol 4: 267-274.

Galiano RD, Michaels Jt, Dobryansky M, Levine JP, Gurtner GC (2004) Quantitative and reproducible murine model of excisional wound healing. Wound Repair Regen 12: 485-492.

Garzon I, Martin-Piedra MA, Alaminos M (2015) Human dental pulp stem cells. A promising epithelial-like cell source. Medical hypotheses 84 516-517.

Garzon I, Martin-Piedra MA, Alfonso-Rodriguez C, Gonzalez-Andrades M, Carriel V, Martinez-Gomez C, Campos A, Alaminos M (2014) Generation of a biomimetic human artificial cornea model using Wharton's jelly mesenchymal stem cells. Invest Ophthalmol Vis Sci 55: 4073-4083.

Garzon I, Martin-Piedra MA, Carriel V, Alaminos M, Liu X, D'Souza RN (2017) Bioactive injectable aggregates with nanofibrous microspheres and human dental pulp stem cells: a translational strategy in dental endodontics. J Tissue Eng Regen Med 12: 204-216.

Garzon I, Miyake J, Gonzalez-Andrades M, Carmona R, Carda C, Sanchez-Quevedo Mdel C, Campos A, Alaminos M (2013) Wharton's jelly stem cells: a novel cell source for oral mucosa and skin epithelia regeneration. Stem Cells Transl Med 2: 625632.

Garzon I, Sanchez-Quevedo MC, Moreu G, Gonzalez-Jaranay M, Gonzalez-Andrades M, Montalvo A, Campos A, Alaminos M (2009a) In vitro and in vivo cytokeratin patterns of expression in bioengineered human periodontal mucosa. J Periodontal Res 44: 588-597.

Garzon I, Serrato D, Roda O, Del Carmen SanchezQuevedo M, Gonzales-Jaranay M, Moreu G, NietoAguilar R, Alaminos M, Campos A (2009b) In vitro cytokeratin expression profiling of human oral mucosa substitutes developed by tissue engineering. Int J Artif Organs 32: 711-719.

Gebremeskel L, Bhoumik D, Sibhat GG, Tuem KB (2018) In vivo wound healing and anti-inflammatory activities of leaf latex of aloe megalacantha baker (xanthorrhoeaceae). Evid Based Complement Alternat Med 2018: 5037912. DOI: 10.1155/2018/5037912.

Germain L, Larouche D, Nedelec B, Perreault I, Duranceau L, Bortoluzzi P, Beaudoin Cloutier C, Genest H, Caouette-Laberge L, Dumas A, Bussiere A, Boghossian E, Kanevsky J, Leclerc Y, Lee J, Nguyen MT, Bernier V, Knoppers BM, Moulin VJ, Auger FA (2018) Autologous bilayered self-assembled skin substitutes (SASSs) as permanent grafts: a case series of 14 severely burned patients indicating clinical effectiveness. Eur Cell Mater 36: 128-141.

Ghatak S, Maytin EV, Mack JA, Hascall VC, Atanelishvili I, Moreno Rodriguez R, Markwald RR, Misra S (2015) Roles of proteoglycans and glycosaminoglycans in wound healing and fibrosis. Int J Cell Biol 2015: 834893. DOI: 10.1155/2015/834893.

Gimble J, Guilak F (2003) Adipose-derived adult stem cells: isolation, characterization, and differentiation potential. Cytotherapy 5: 362-369.

Gronthos S, Mankani M, Brahim J, Robey PG, Shi S (2000) Postnatal human dental pulp stem cells (DPSCs) in vitro and in vivo. Proc Natl Acad Sci U S A 97: 13625-13630.

Hartmann-Fritsch F, Biedermann T, Braziulis E, Luginbuhl J, Pontiggia L, Bottcher-Haberzeth S, van Kuppevelt TH, Faraj KA, Schiestl C, Meuli M, Reichmann E (2016) Collagen hydrogels strengthened by biodegradable meshes are a basis for dermoepidermal skin grafts intended to reconstitute human skin in a one-step surgical intervention. J Tissue Eng Regen Med 10: 81-91.

Joerger-Messerli MS, Marx C, Oppliger B, Mueller M, Surbek DV, Schoeberlein A (2016) Mesenchymal stem cells from Wharton's jelly and amniotic fluid. Best Pract Res Clin Obstet Gynaecol 31: 30-44.

Kim HJ, Park JS (2017) Usage of human mesenchymal stem cells in cell-based therapy: advantages and disadvantages. Dev Reprod 21: 1-10.

Kim HJ, Tinling S, Chole R (2002) Expression patterns of cytokertins in cholesteatomas: evidence of increased migration and proliferation. J Korean Med Sci 17: 381-388

Klar AS, Michalak K, Bottcher-Haberzeth S, Reichmann E, Meuli M, Biedermann T (2018) The expression pattern of keratin 24 in tissue-engineered dermo-epidermal human skin substitutes in an in vivo model. Pediatr Surg Int 34: 237-244.

Kober J, Gugerell A, Schmid M, Zeyda M, Buchberger E, Nickl S, Hacker S, Ankersmit HJ, Keck M (2016) Wound healing effect of conditioned media obtained from adipose tissue on human skin cells: a comparative in vitro study. Ann Plast Surg 77: 156-163.

Kokubun K, Pankajakshan D, Kim MJ, Agrawal DK (2016) Differentiation of porcine mesenchymal stem cells into epithelial cells as a potential therapeutic application to facilitate epithelial regeneration. J Tissue Eng Regen Med 10: E73-83.

Koppula PR, Chelluri LK, Polisetti N, Vemuganti GK (2009) Histocompatibility testing of cultivated human bone marrow stromal cells - a promising step 
towards pre-clinical screening for allogeneic stem cell therapy. Cell Immunol 259: 61-65.

Kraft R, Herndon DN, Al-Mousawi AM, Williams FN, Finnerty CC, Jeschke MG (2012) Burn size and survival probability in paediatric patients in modern burn care: a prospective observational cohort study. Lancet 379: 1013-1021.

Larouche D, Cantin-Warren L, Desgagne M, Guignard R, Martel I, Ayoub A, Lavoie A, Gauvin R, Auger FA, Moulin VJ, Germain L (2016) Improved methods to produce tissue-engineered skin substitutes suitable for the permanent closure of full-thickness skin injuries. Biores Open Access 5: 320-329.

Le Blanc K, Ringden O (2005) Immunobiology of human mesenchymal stem cells and future use in hematopoietic stem cell transplantation. Biol Blood Marrow Transplant 11: 321-334.

Lee JH, Park HJ, Kim YA, Lee DH, Noh JK, Kwon CH, Jung SM, Lee SK (2012) Differentiation and major histocompatibility complex antigen expression in human liver-derived stem cells. Transplant Proc 44: 1113-1115.

Llames SG, Del Rio M, Larcher F, Garcia E, Garcia M, Escamez MJ, Jorcano JL, Holguin P, Meana A (2004) Human plasma as a dermal scaffold for the generation of a completely autologous bioengineered skin. Transplantation 77: 350-355.

Lloyd C, Besse J, Boyce S (2015) Controlledrate freezing to regulate the structure of collagenglycosaminoglycan scaffolds in engineered skin substitutes. J Biomed Mater Res B Appl Biomater 103: 832-840.

Lohan P, Coleman CM, Murphy JM, Griffin MD, Ritter T, Ryan AE (2014) Changes in immunological profile of allogeneic mesenchymal stem cells after differentiation: should we be concerned? Stem Cell Res Ther 5: 99. DOI: 10.1186/scrt488.

Lohan P, Treacy O, Griffin MD, Ritter T, Ryan AE (2017) Anti-donor immune responses elicited by allogeneic mesenchymal stem cells and their extracellular vesicles: are we still learning? Front Immunol 8: 1626. DOI: 10.3389/fimmu.2017.01626.

Losk K, Vaz-Luis I, Camuso K, Batista R, Lloyd M, Tukenmez M, Golshan M, Lin NU, Bunnell CA (2016) Factors associated with delays in chemotherapy initiation among patients with breast cancer at a comprehensive cancer center. J Natl Compr Canc Netw 14: 1519-1526.

Ma T, Wang X, Jiang D (2017) Immune tolerance of mesenchymal stem cells and induction of skin allograft tolerance. Curr Stem Cell Res Ther 12: 409415.

Maere S, Heymans K, Kuiper M (2005) Bingo: A cytoscape plugin to assess overrepresentation of gene ontology categories in biological networks. Bioinformatics 21: 3448-3449.

Mahdavishahri N, Moghatam Matin M, Fereidoni M, Yarjanli Z, Banihashem Rad SA, Khajeh Ahmadi $S$ (2012) In vitro assay of human gingival scaffold in differentiation of rat's bone marrow mesenchymal stem cells to keratinocystes. Iran J Basic Med Sci 15: 1185-1190.

Martin-Piedra MA, Garzón I, Gómez-Sotelo A, Garcia-Abril E, Jaimes-Parra BD, López-Cantarero M, Alaminos M, Campos A (2017) Generation and evaluation of novel stromal cell-containing tissue engineered artificial stromas for the surgical repair of abdominal defects. Biotechnol J 12. DOI: 10.1002/ biot.201700078,

Mendez JJ, Ghaedi M, Steinbacher D, Niklason LE (2014) Epithelial cell differentiation of human mesenchymal stromal cells in decellularized lung scaffolds. Tissue Eng Part A 20: 1735-1746.

Moravvej H, Hormozi AK, Hosseini SN, Sorouri R, Mozafari N, Ghazisaidi MR, Rad MM, Moghimi MH, Sadeghi SM, Mirzadeh H (2016) Comparison of the application of allogeneic fibroblast and autologous mesh grafting with the conventional method in the treatment of third-degree burns. J Burn Care Res 37: e90-95.

Park SA, Teixeira LB, Raghunathan VK, Covert J, Dubielzig RR, Isseroff RR, Schurr M, Abbott NL, McAnulty J, Murphy CJ (2014) Full-thickness splinted skin wound healing models in $\mathrm{db} / \mathrm{db}$ and heterozygous mice: implications for wound healing impairment. Wound Repair Regen 22: 368-380.

Pensalfini M, Ehret AE, Studeli S, Marino D, Kaech A, Reichmann E, Mazza E (2017) Factors affecting the mechanical behavior of collagen hydrogels for skin tissue engineering. J Mech Behav Biomed Mater 69: 85-97.

Pittenger MF, Mackay AM, Beck SC, Jaiswal RK, Douglas R, Mosca JD, Moorman MA, Simonetti DW, Craig S, Marshak DR (1999) Multilineage potential of adult human mesenchymal stem cells. Science 284: 143-147.

Proksch E, Brandner JM, Jensen JM (2008) The skin: an indispensable barrier. Exp Dermatol 17: 1063-1072.

Reinders ME, de Fijter JW, Roelofs H, Bajema IM, de Vries DK, Schaapherder AF, Claas FH, van Miert PP, Roelen DL, van Kooten C, Fibbe WE, Rabelink TJ (2013) Autologous bone marrow-derived mesenchymal stromal cells for the treatment of allograft rejection after renal transplantation: results of a phase I study. Stem Cells Transl Med 2: 107-111.

Reuter C, Walles H, Groeber F (2017) Preparation of a three-dimensional full thickness skin equivalent. Methods Mol Biol 1612: 191-198.

Rodriguez IA, Lopez-Lopez MT, Oliveira AC, Sanchez-Quevedo MC, Campos A, Alaminos M, Duran JD (2012) Rheological characterization of human fibrin and fibrin-agarose oral mucosa substitutes generated by tissue engineering. J Tissue Eng Regen Med 6: 636-644.

Shi M, Liu ZW, Wang FS(2011)Immunomodulatory properties and therapeutic application of mesenchymal stem cells. Clin Exp Immunol 164: 1-8.

Smola H, Thiekotter G, Fusenig NE (1993) Mutual induction of growth factor gene expression by 
epidermal-dermal cell interaction. J Cell Biol 122: 417-429.

Strong AL, Neumeister MW, Levi B (2017) Stem cells and tissue engineering: regeneration of the skin and its contents. Clin Plast Surg 44: 635-650.

Vig K, Chaudhari A, Tripathi S, Dixit S, Sahu R, Pillai S, Dennis VA, Singh SR (2017) Advances in skin regeneration using tissue engineering. Int J Mol Sci 18: pii: E789. DOI: 10.3390/ijms18040789.

Wang C, Zhu H, Sun Z, Xiang Z, Ge Y, Ni C, Luo Z, Qian W, Han X (2014) Inhibition of wnt/betacatenin signaling promotes epithelial differentiation of mesenchymal stem cells and repairs bleomycininduced lung injury. Am J Physiol Cell Physiol 307: C234-244.

Wang HS, Hung SC, Peng ST, Huang CC, Wei HM, Guo YJ, Fu YS, Lai MC, Chen CC (2004) Mesenchymal stem cells in the Wharton's jelly of the human umbilical cord. Stem Cells 22: 1330-1337.

Weiss ML, Anderson C, Medicetty S, Seshareddy KB, Weiss RJ, VanderWerff I, Troyer D, McIntosh KR (2008) Immune properties of human umbilical cord Wharton's jelly-derived cells. Stem cells (Dayton, Ohio) 26: 2865-2874.

Yamada N, Uchinuma E, Kuroyanagi Y (2012) Clinical trial of allogeneic cultured dermal substitutes for intractable skin ulcers. J Artif Organs 15: 193-199. Zhang WB, Cheng MJ, Huang YT, Jiang W, Cong Q, Zheng YF, Xu CJ (2012) A study in vitro on differentiation of bone marrow mesenchymal stem cells into endometrial epithelial cells in mice. Eur J Obstet Gynecol Reprod Biol 160: 185-190.

Zuk PA, Zhu M, Ashjian P, De Ugarte DA, Huang JI, Mizuno H, Alfonso ZC, Fraser JK, Benhaim P, Hedrick MH (2002) Human adipose tissue is a source of multipotent stem cells. Mol Biol Cell 13: 4279-4295.

\section{Discussion with Reviewer}

Reviewer: What are next steps for the development of this bioengineered skin substitute to obtain an epidermis similar to human skin with terminally differentiated epithelial cell layers on the entire surface?

Authors: The promising results of the study lead to the hypothesis that the HHS generated could have future clinical translation potential. Therefore, next steps should include fulfilling the requirements of the European Medicines Agency for Advanced Therapies, including the preclinical characterisation at the biomechanical, physiological and optical (UV absorbance, speckle pattern) levels. In addition, improving the current HHS model by incorporating vascular progenitors in order to achieve vascularised models is in progress.

Reviewer: Several studies have shown the reexpression of HLA upon differentiation of stem cells (Lee et al., 2012; Lohan et al., 2014). Could the authors comment on the possibility that HLA could be re-expressed when the epidermis will be fully differentiated?

Authors: This is an important issue as HHS cells could express HLA markers after full differentiation, as described for bone and cartilage tissue substitutes (Lee et al., 2012; Lohan et al., 2014; Lohan et al., 2017). However, the lack of information related to HLA expression on epithelial differentiation of MSCs point out the importance to perform further research in this field.

Editor's note: The Scientific Editor responsible for this paper was Mauro Alini. 